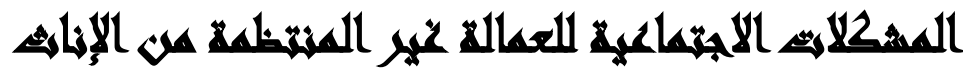

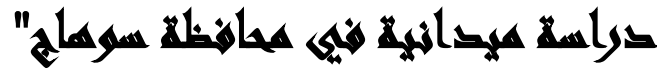

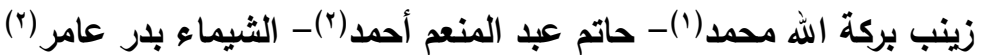

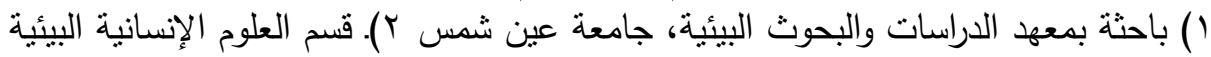

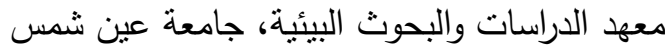

\section{المستخلصى}

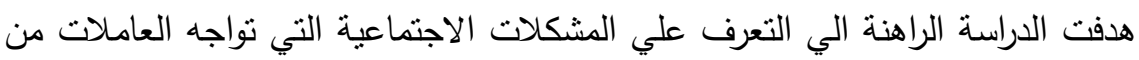

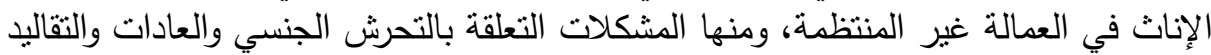

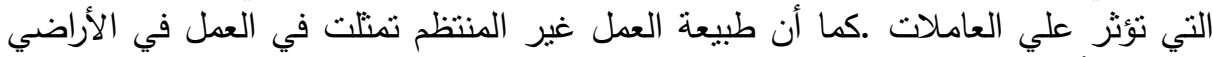

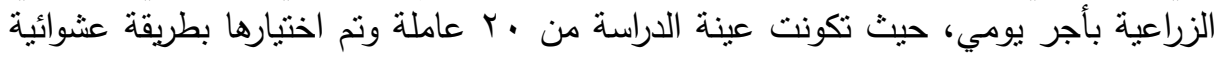

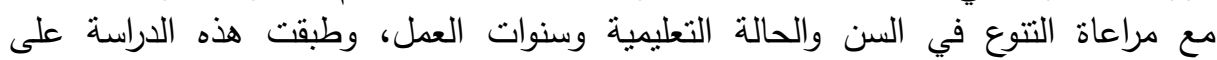
العاملات في الأراضي الزراعية في أحدي قري الصعيد - قرية عنيبس - التابعة لمركز جعينة

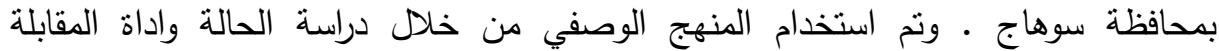

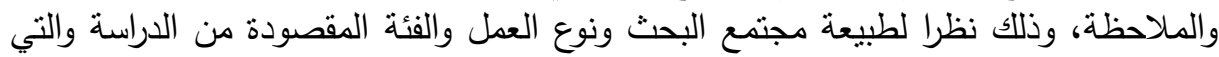

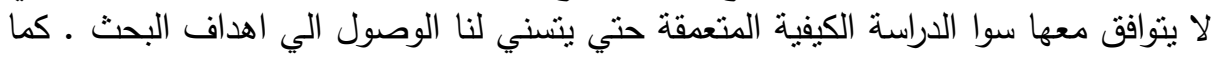

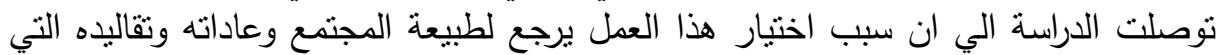

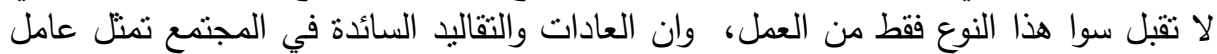

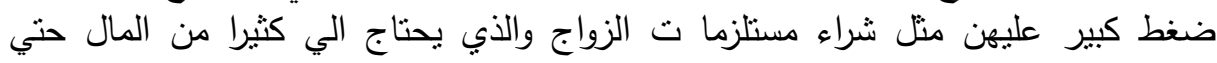

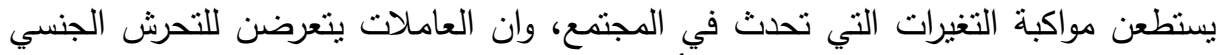

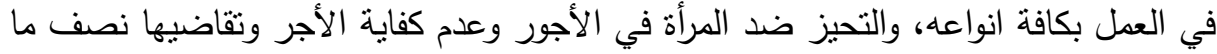

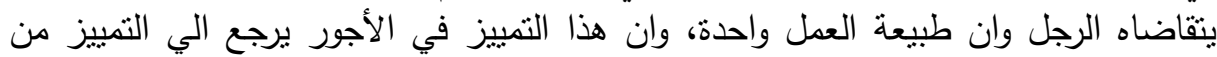

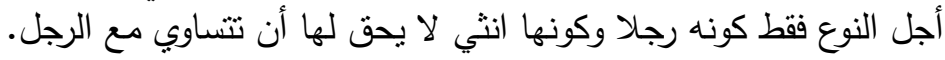

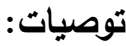

- ويوصي البحث قيام المجتمع المحلي بدوره اتجاه الفئات الفقيرة في المجتمع وخاصة في قري الصعيد.

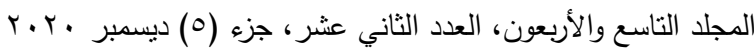

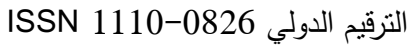


- كما يوصي الباحثون علي المجلس القومي للمرأة الاهتمام بهذه الفئات المهششة من الإناث

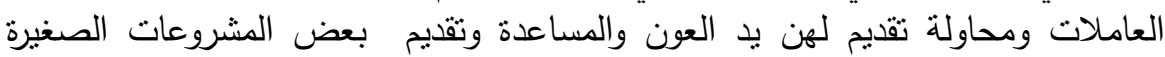

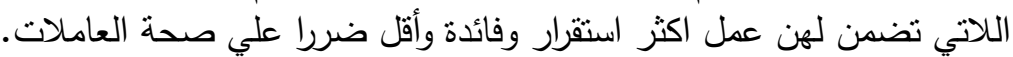

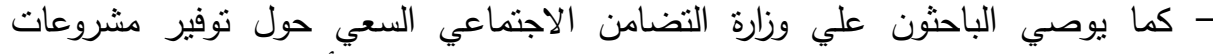

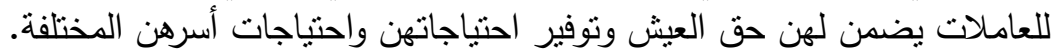

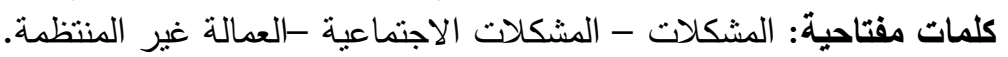

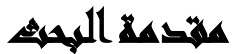

تمنل التتمية الثناملة الهدف الاساسي للمجمعات البثرية، فالتتمية هي الطريق الامتل للاستفادة من الامكانات البشرية والمادية المتاحة، كما ان التتمية تمثل كافة مجالات الحياه الاقتصادية والتعليمية والثقافية والبشرية والتكنولوجية وغير الكثير من جوانب الحياه. فالإنسان هو العنصر الاساسي والاهم في العملية التتموية وهو الذي تقوم عليه ارجاء عملية التتمية وعندما نتحدث عن الانسان بالطبع نقصد به الرجل والمرأة، فمساهمة المرأة في

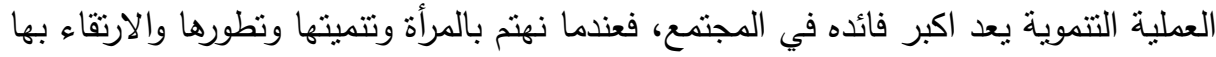
فهذا يعني الاهتمام بالمتمع بأكمله كونها الام والاخت والزوجة والمربية والمعلمة لها مالها

من الادوار المتعددة والتي تجعلها محض اهتمام كبير ولها تأثير بالغ علي المجتمع بأكمله .

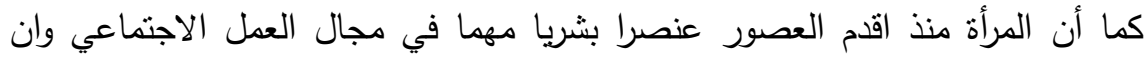
كانت تتغير مهامها تبعا لأساليب تقسيم العمل والأدوار الاجتماعية بينها وبين الرجل والتي فهري

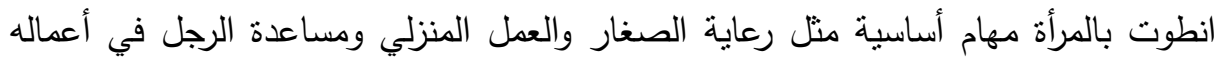
المختلفة. ومع تقدم المجتمعات وانتتار التعليم وتطور التكنولوجيا تغيرت ادوار المرأة وتعددت الاعمال التي تقوم بها. ولقد شهدت السنوات الأخيرة تصاعداً ملحوظاً في حجم الاهتمام الدولي بقضايا المرأة،

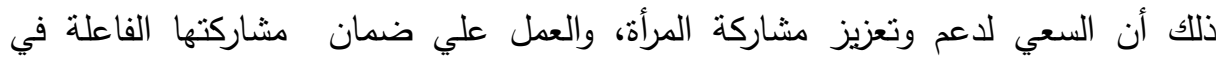

$$
\begin{aligned}
& \text { r.r. المجلد التاسع والأربعون، العدد الثاني عشر، جزء (0) ديسمبر }
\end{aligned}
$$

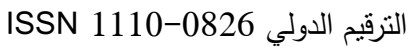


المجتمع، ويأتي ذلك انطلاقا من الترابط الوثيق بين تتمية المرأة وبين النجاح في تحقيق التتمية

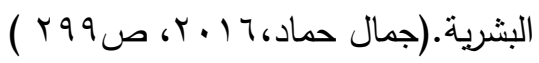

ولا شك في الدور الفاعل للمرأة العربية الريفية في الانتاج الزراعي ولا سيما في البلدان

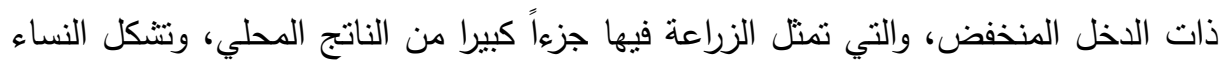

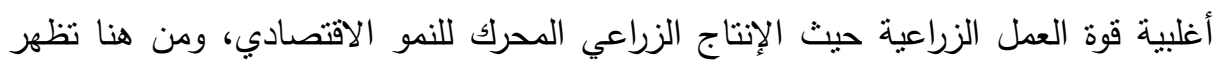

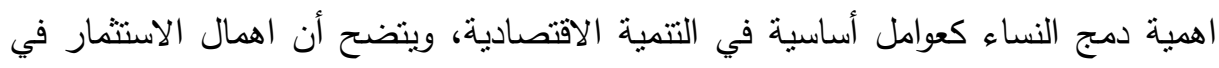
النساء يعوق جهود الحد من الفقر ويضعف عائد التتمية الاقتصادية والاجتماعية(مرفت، ( rOV G. T. V

وعندما نتحدث عن خروج المرأة الي هذا النوع من العمل الثناق الغير منتظم فمن المؤكد

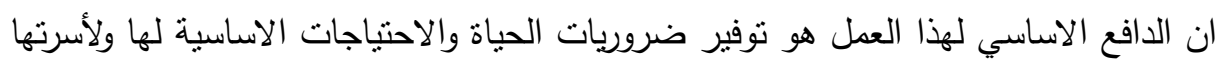
ومن تعولهم، وعندمنا لا يتوافر امامها فرص عمل سوي العمل الثناق في الاراضي الزراعية

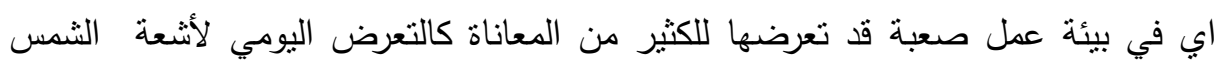
شديدة الحرارة والتعرض للأتربة وحمل الاثياء الثقيلة وانتثار الحشرات في بيئة العمل وغيره

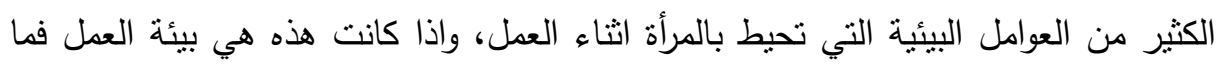
الدافع حول خروج المرأة الي هذا العمل سوا الفقر والوضع الافتصادي المتدني الذي دفعها لتهاه الي الخروج للعمل في سن مبكر، والحرمان من اكمال التعليم والحصول علي شهاده.

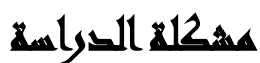

تتمية المرأة من اهم عمليات التنمية وان اهمال المرأة وعدم تتميتها يعني وجود الكثير

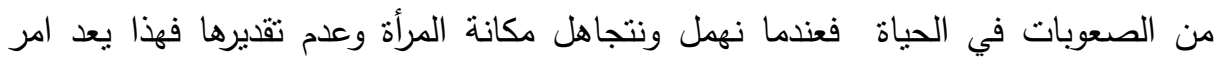
خطير للغاية، وله عواقب كبيره يصعب حصرها، كما ان تتمية المرأة احد الركائز الأساسية التي تقوم عليها العملية التتموية .

$$
\begin{aligned}
& \text { r.r. المجلد الناسع والأربعون، العدد الثاني عشر، جزء (0) ديسمبر } \\
& \text { الترقيم الدولي 0826- ISSN 1110 }
\end{aligned}
$$


وأضافة دراسة جمال محمد الي اثثارة تقرير الاحصاء في الامم المتحدة لعام

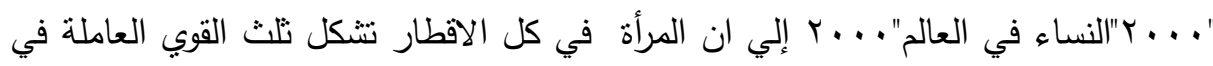

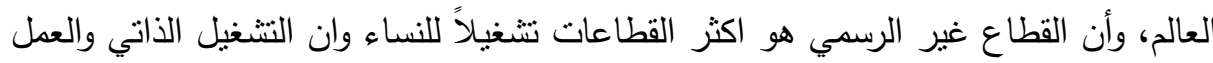
الجزئي وعمل الانتاجي المنزلي مما ضاعف فرص العمل للنساء غير ان عمل المرأة مازال ينركز في القطاعات ومجالات محدودة وفرصها في العمل الرسمي اقل من الفرص المتاحة

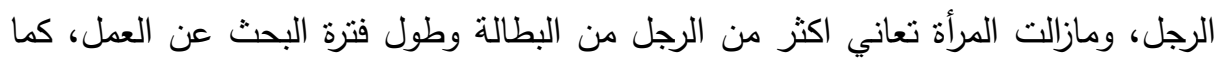
تحتل مراتب ادني من الرجل في السلم الوظيفي وتنقاضي اجور اقل وتحتل الوظائف التي لتراني

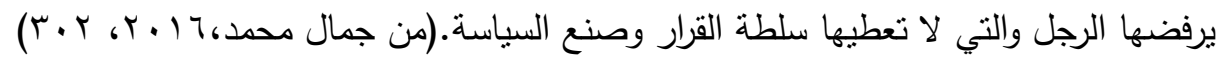
كما ان المرأة تتعرض لكثيرا من المعاناة في العمل غير المنتظم واهدار حقوقها، لهنها، واستغلالها بطرق مختلفة مثل التحيز في الاجور، وطول ساعات العمل نظرا لحاجتهن

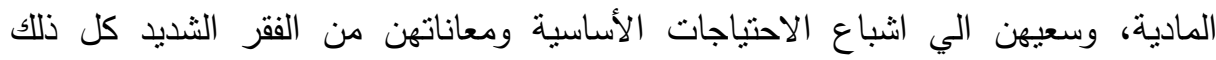
يجعلهن يتقبلن كافة ما يتعرضن له من مشكلات مختلفة في العمل غير المنتظم. وتؤكد تقارير البنك الدولي انه لا توجد دولة في العالم تتساوي فيها الحقوق الاجنماعية

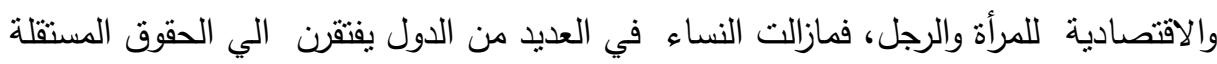
في ملكية الاراضي وإدارة الممتلكات والاعمال، او حتي السفر دون موافقة ازواجهن (البنكاه

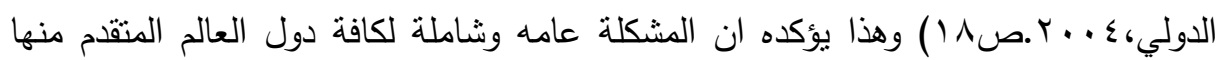
والنامي جميعهم لا يعطون للمرأة حقها في المجتمع، كما ان سيطرة الرجل علي فكر المجتمع ونئه

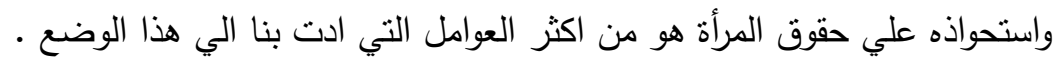
كما وضحت الاحصاءات ان نسبة العاملات في قطاع الزراعة نختلف من دولة إلي

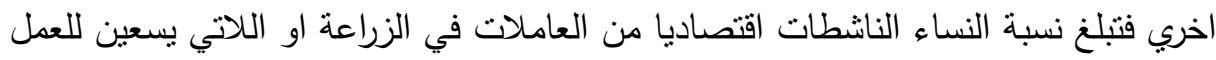

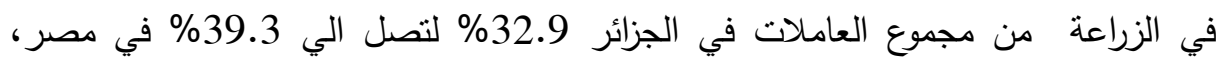
و 49.1في المغرب و 8.6في ليبيا، وتبلغ في السودان 65.1\%، وفي تونس تصل الي 24,6 وفي الاردن تصل الي 22.4 \% ،وفي فلسطين تصل نسبة العاملات الي 22.2 244

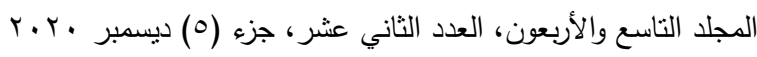

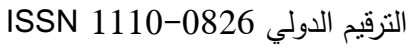


وتبلغ 61.9\% في اليمن وفي السعودية 1.8\% (تقرير حالة الاغذية والزراعة، 11، بـ، $\left.\left(\wedge 7_{6}\right) \cdot 0,1\right) \cdot V$

فقد اشارت احدي الدراسات الي ان اجور الاناث تتخفض عن أجور الذكور في القطاع غير الرسمي، فمثلا يقدر اجر المرأة في المنوسط بنحو 60\% من منوسط اجر الرجل الربل

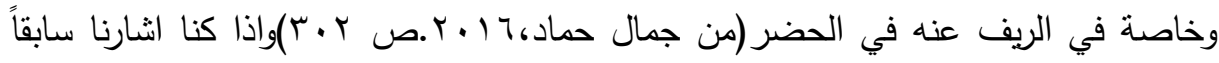
بأن التميز ضد المرأة في العمل هو امر شائع في دول العالم فيكيف بالمجتمعات الريفية

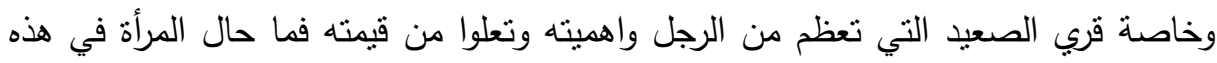

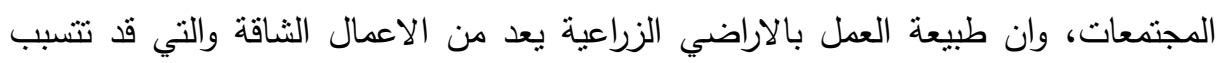

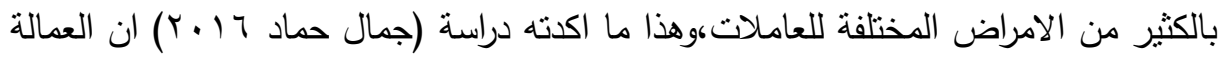
غير المنتظمة تعاني من قلة الموارد المالية مما يؤثر علي تعليمها او تعليم ابنائها، وتؤكد

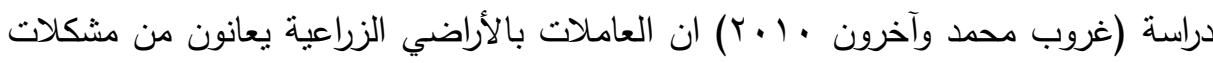

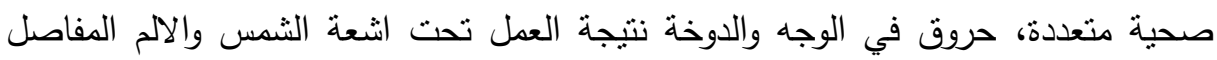

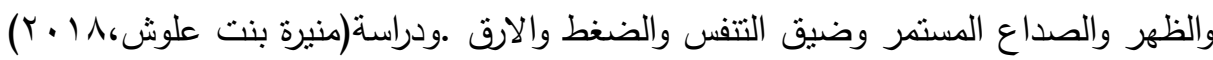

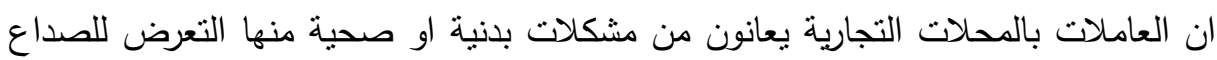

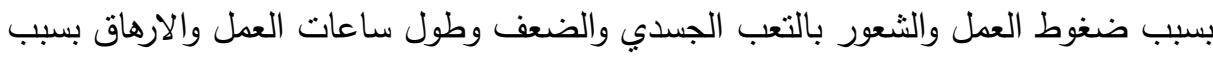

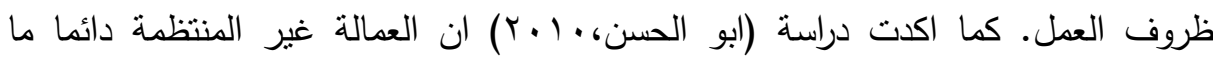
يعانون من تدهور في الحالة الصحية لدي العاملون • بالإضافة الي دراسة (جمزه جواد، بدون

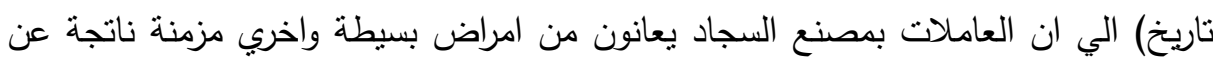
العمل. ومن خلال المنطلقات النظرية التي تقوم عليها الدراسة تأكدت الباحثة بأنه العمالة غير المنتظمة من الإناث نواجه مشكلات اجتماعية كالعمل في سن مبكر والحرمان من التعليم

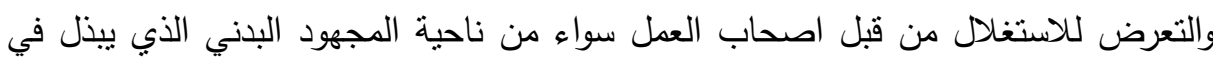

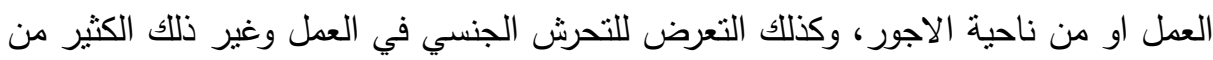

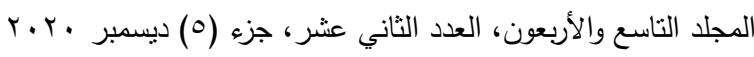

$$
\begin{aligned}
& \text { الترقيم الدولي 0826-1110 }
\end{aligned}
$$




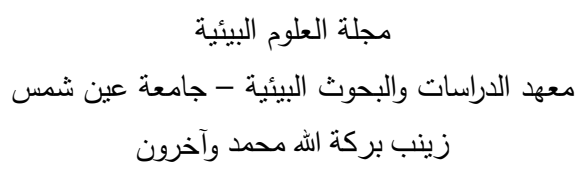

المشكلات ومن هنا امكن تحديد مشكلة الدراسة في المشكلات الاجتماعية للعمالة المنتظمة من الإناث.

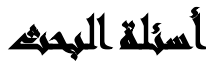

1- ما مدي تعرض العاملات للتحرش الجنسي او اللفظي اثثاء العمل ؟

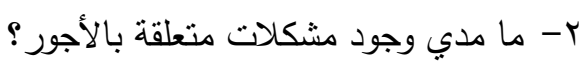

r- ما العادات والتقاليد السائدة في المجتمع التي تؤثر بشكل سلبي علي مجتمع الدراسة؟

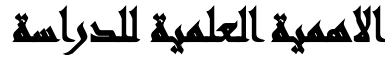

تعددت الدراسات والابحاث التي تهتم بمشكلات المرأة وخاصة المرأة العاملة كما تتاولها البعض من اتجاهات مختلفة فالبعض تتاول دوافع عمل المرأة والبعض الاخر نتاول المشكلات

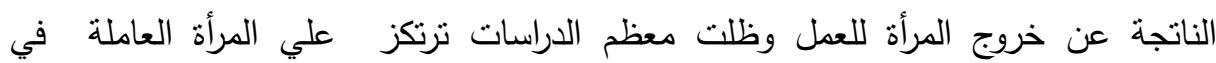
القطاعات الرسمية او في العمل المنتظم، ولكن اهم ما يميز دراستتا الحالية هي انها تركز

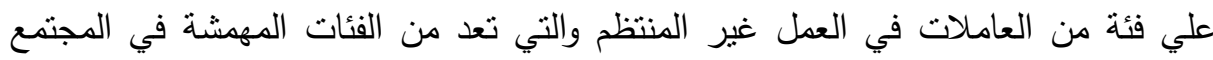

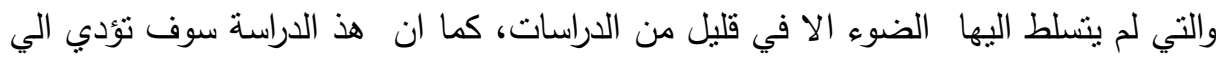
ثراء معرفي في البحوث والدراسات العلمية نظرا لتتاولها عدة مشكلات مختلفة متعلقة بعمالة المرأة في المناطق الريفية وهي المشكلات الاجنماعية التي يعانين منها العاملات في العمل غير المنتظم فئن

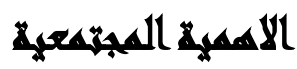

قد تستطيع كل فئه في المجتمع ان تجلي بصوتها في التوضيح والتحدث عن المعاناة او

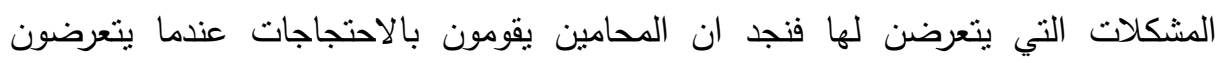

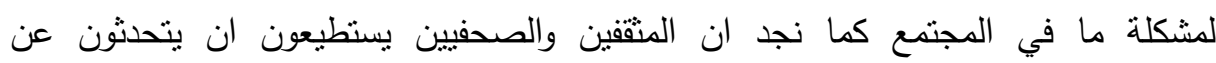
مشكلاتهم وعرضها وتصعيدها الي من يهمه الامر نظراً لمكانتهم في المجتمع وكذلك نوافر

$$
\begin{aligned}
& \text { r.r. المجلد الناسع والأربعون، العدد الثاني عشر ، جزء (0) ديسمبر }
\end{aligned}
$$

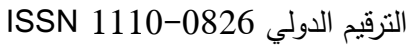


المعرفة لديهم في التعبير عن مشكلاتهم واحتياجاتهم المختلفة، ولكن عندما يكون هنآك جماعات في المجتمع او فئات معينة لم تحظي بقدر من العلم او المعرفة يتعرضون

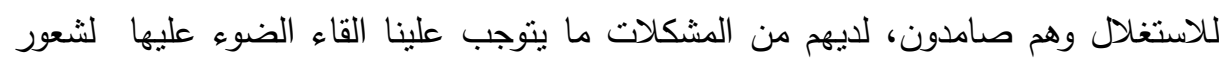
الاخرين بها او لقيام الدولة بالنظر اليهن ومعرفة مشكلاتهن ومعاناتهن المختلفة، وهذه الفئه

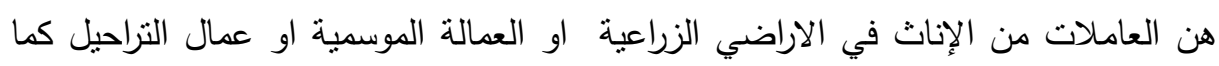

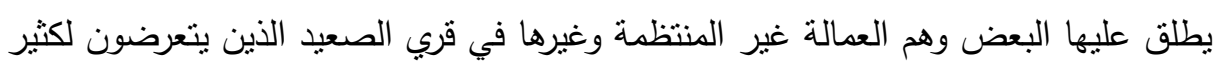
من الضغوطات والمشكلات المختلفة، مما يتوجب علينا كباحثين ومن منطلق الدوافع الانسانية الاهتمام بهم وبقضاياهم ومشكلاتهم المختلفة كالتحرش الجنسي والاستغلال من قبل اصحاب العمل نظرا لطبيعة العمل الذي لا تحكمه اية لوائح او قوانين.

\section{أهماهيم الصوراسة}

1- الكثف عن المشكلات الخاصة بالتحرش الجنسي في العمل.

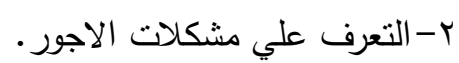
r-الكثف عن المشكلات الاجتماعية المتعلقة بالعادات والتقاليد الاجتماعية المؤثرة علي مجتمع الدراسة.

\section{مهخاهيه الهيهي}

أولاً : المشكلة الاجتماعية Social problem: التعريف الإجرائي للمشكلة الاجتماعية:

• التعرف علي مشكلة التحرش الجنسي التي تتعرض لها العامله في العمالة غير المنتظمة. • التعرف على المشكلات المتعلقة بالأجور والوضع الاقتصادي والاجتماعي لأسر العاملات.

• التعرف على المشكلات المتعلقة بالعادات والتقاليد الاجتماعية التي تواجه العاملات.

$$
\begin{aligned}
& \text { r.r. المجلد التاسع والأربعون، العدد الثاني عثر، جزء (0) ديسمبر } \\
& \text { التزقيم الدولي 0826-08 1110 }
\end{aligned}
$$


ثانياً: تعريف العمالة غير المنتظمة:

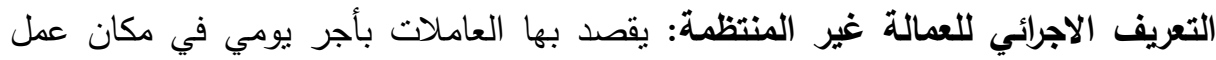

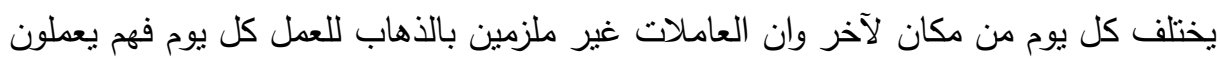

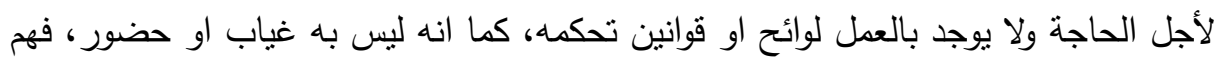

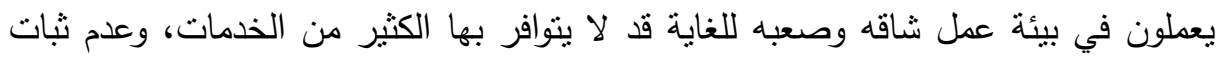

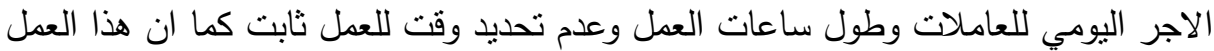
لا يتطلب مستوي علمي معين بل لا يحتاج غالبا الا الي المجهود البدني والعضلي الكبير والعاملين به من اعمار مختلفة اطفال وشباب وإناث، يعمل به جميع الفئات العمرية الدختلفة.

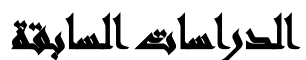

(1) دراسة بعنوان "دور واقع التمكين الاقتصادي للمرأة في القطاع غير الرسمي، دراسة

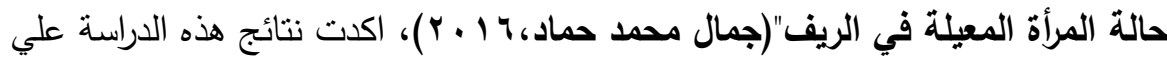

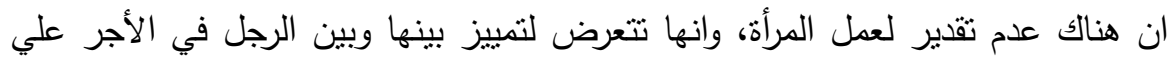

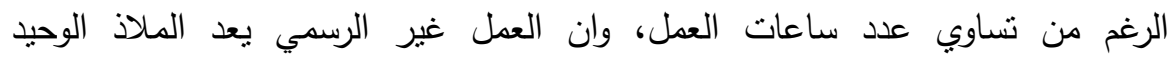

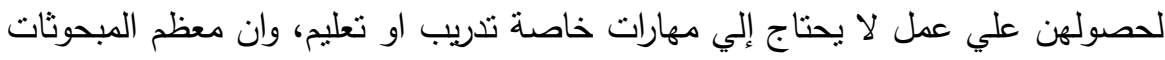

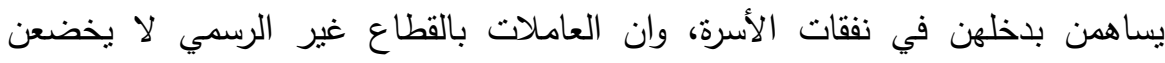

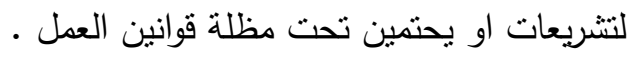

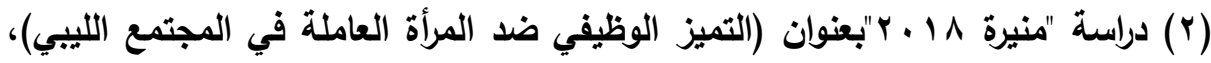

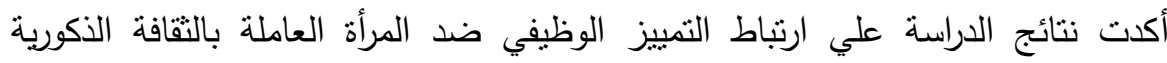

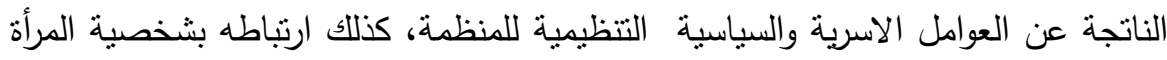

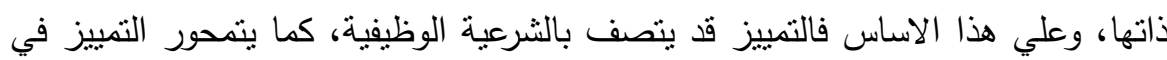

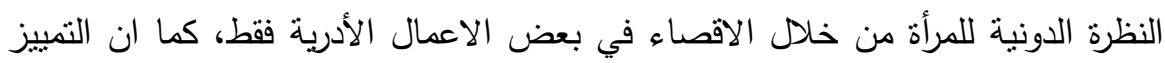
يرجع الي المرأة العاملة ذاتها بسبب جهالها بالقوانين والحقوق.

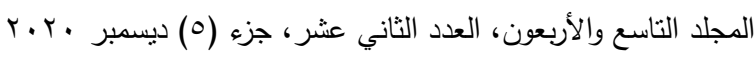

$$
\begin{aligned}
& \text { الترقيم الدولي 0826-1110 }
\end{aligned}
$$




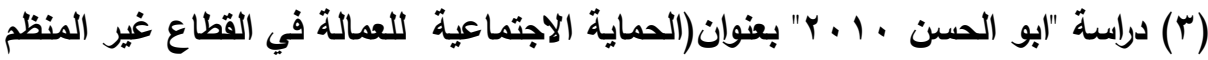

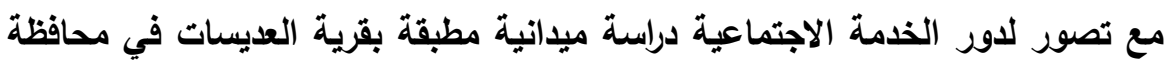

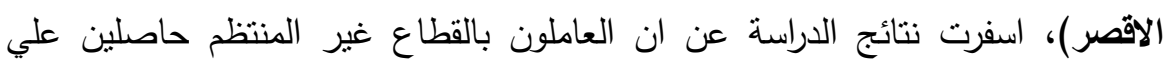
مؤهل متوسط ويعولون اسر تتكون من V افراد، وان العاملون يشعرون بأن ظروفهم اسوء باء من غيرهم والثعور بعدم الامن والخوف من المستقبل، والخجل من وضعهم الاقتصادي،

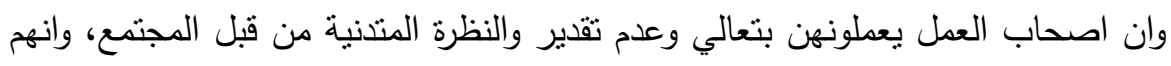
يعملون من اجل لقمة العيش مع عدم الطموح، ويجدون صعوبة في الموازنة بين دخولهم ومصاريف اسرهم، والتدهور المستمر في حالتهم الصحية.

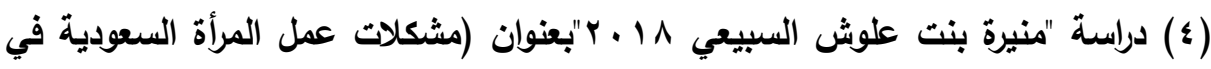
المحلات التجارية، دراسة ميدانية علي محافظة الرياض والخرج)، اسفرت نتائج الدراسة

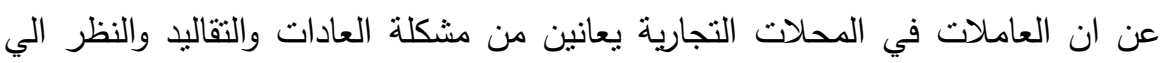
البائعة نظرة سلبيه ومتدنية، وان العاملات غير راضيات عن العمل، والمعاملة الغير طييه

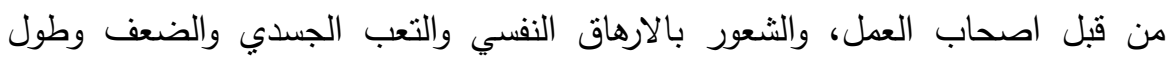
ساعات العمل، والشعور بالاكتئاب والإحساس بالنقص لعدم مناسبة العمل لهن.

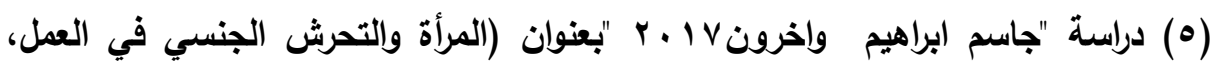

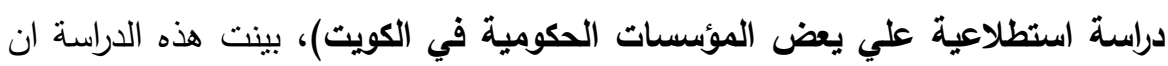

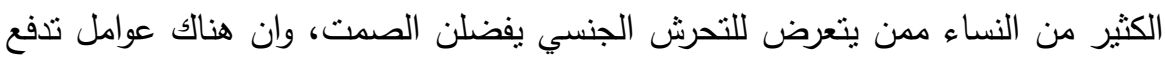

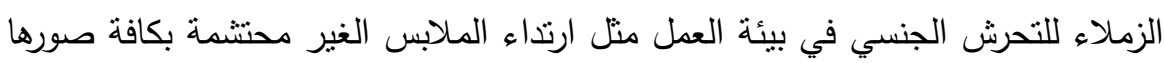

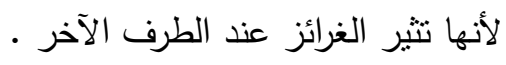

(7) واثثتت دراسة(Fornier, Anneleen Erika Hendrika Cornelia، العمالة غير المنتظمة قد اصبحت من الظواهر التي نتزايد بشكل واضح للغاية ومنتشرة في الاسواق، وتتثعر هذه الفئة دوما بفقدان الامن وعدم الثعور بالطمأنينة وقد أكدت الدراسة

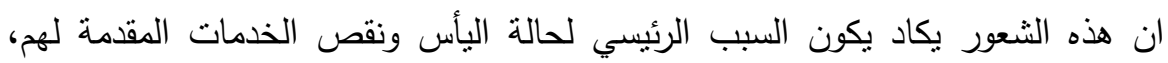

$$
\begin{aligned}
& \text { r.r. . المجلد التاسع والأربعون، العدد الثاني عشر، جزء (0) ديسمبر } \\
& \text { الترقيم الدولي 0826- ISSN 1110 }
\end{aligned}
$$


وتوصي الدراسة بضرورة عمل عقود طويلة المدي لهذه العمالة وخاصة ان هذه الفئة تتعرض للمخاطر وفقدان العمل وعدم التمتع بالمزايا القانونية وعدم توافر الحماية الكافية

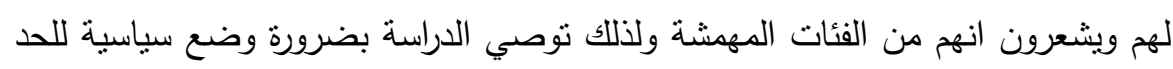
من هذه التحديات وتقليل الثعور بعدم الامان من خلال عمل عقود للعمالة الغير منظمة ولثة وقليلة الاجل وتوفير الرعاية المتكاملة لهم.

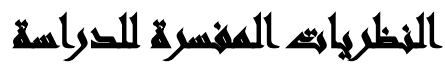

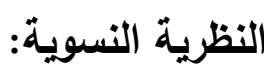

للنظرية النسوية تاريخ طويل سواء من حيث محاولة فهم وضع كل من الرجل والمرأة

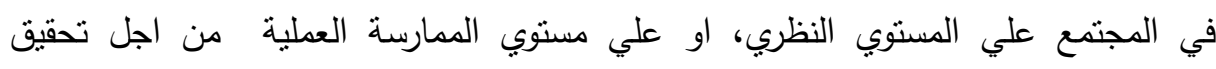
المساواة والعدالة للمرأة في المجتمع، ولكن جوهر التحليلات النسوية واحد في جوهره ومؤداه

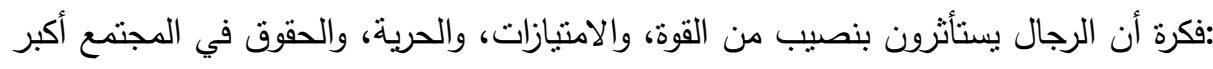

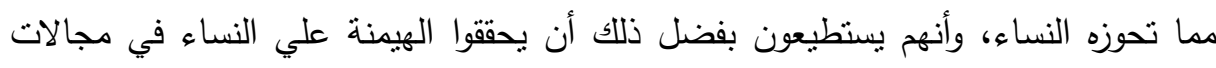
عديدة :كالعمل، وقضاء وقت الفراع داخل البيت، وفي مؤسسات التعليم، وترتبط الاختلافات ولتهات بين توجهات المدارس النسوية المختلفة بتصور مدي التقسيمات والفروق بين النوعين (الذكور

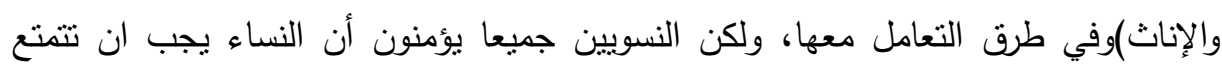

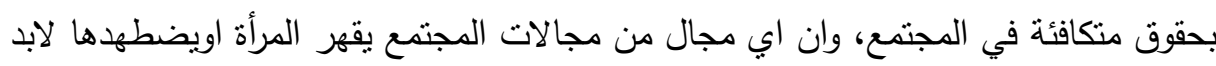

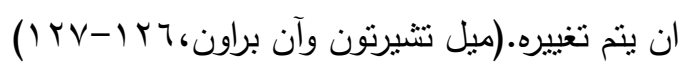
تتفق هذه النظرية مع دراستتا من حيث تفسيرها للأوضاع الراهنة للمرأة العاملة بالعمالة

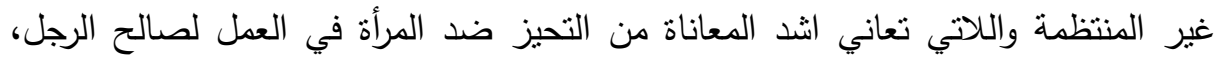
والتقرقة في الأجور بين المرأة والرجل علي اساس النوع مع ان طبيعة العمل واحده وساعات

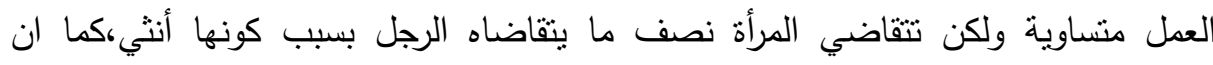
العاملة تعاني من النظرة المتدنية من قبل المجتمع إزاء عملها الغير منتظم وان هذه النظرة لاهي لاهل 250

$$
\begin{aligned}
& \text { r.r. المجلد التاسع والأربعون، العدد الثاني عشر، جزء (0) ديسمبر }
\end{aligned}
$$

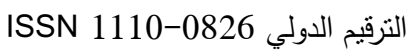


ينظرها المجتمع للرجل، كما ان حالة الفقر اللاتي تعانين منها تجعلها تحرم من حقوقها

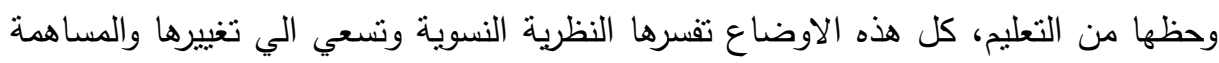

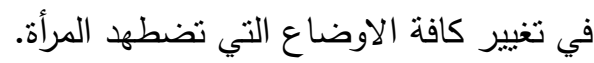
النظرية البنائية الوظيفية:

ظهرت البنائية الوظيفية في نهاية القرن التاسع عشر وبداية القرن العشرين، وجاءت

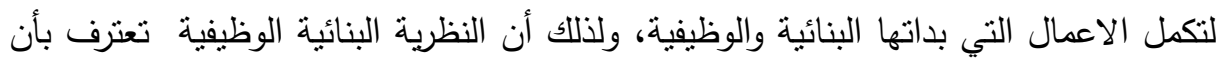

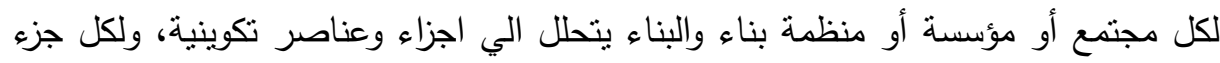
او عنصر وظيفة تساعد علي ديمومة المجتمع أو المؤسسة أو المنظمة، لذا تعترف ببناء الكيانات أو الوحدات الاجتماعية وتعترف في الوقت ذاته بالوظائف التي تؤديها الاجزاءوالعناصر الاولية للبناء أو المؤسسة ووظائف المؤسسة الواحدة لبقية المؤسسات الآخري

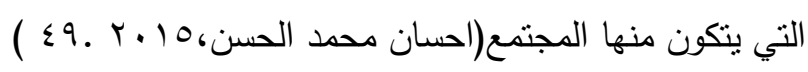
فإذا كانت النظرية البنائية الوظيفية تقوم علي ان المجتمع عبارة عن كل يتكون من مجموعة من الاجزاء التي يكمل بعضها البعض وتؤثر وتتأثر وان اي خلل يصيب جزء من لهن اجزاء المجتمع سوف يعود اثره علي البناء الاجتماعي بشكل عام، وعندما يخفق احد هذه لهاء لهاء

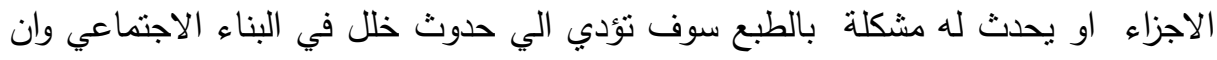
علي المجتمع واجزاؤه ان يقوموا بواجباتهم حتي يحدث التوازن في المجتمع بين كافة الاجزاء

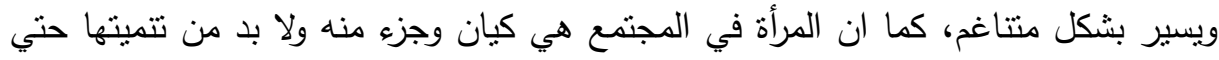

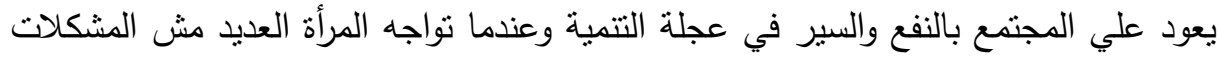

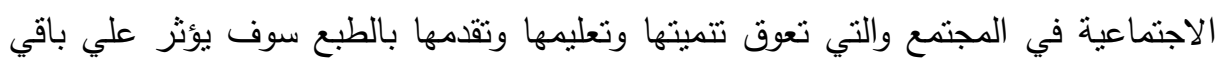

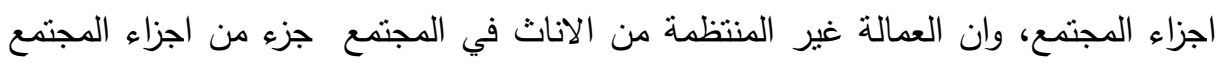

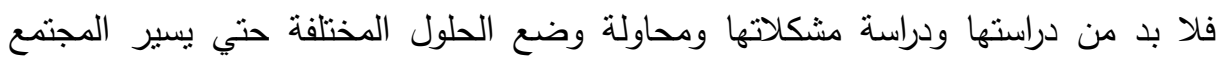
بشكل طبيعي وان لا يتعرض لحالة من التغير الاجتماعي التي قد تؤثر بالسلب علي نوازن ودربن

$$
\begin{aligned}
& \text { r.r. المجلد الناسع والأربعون، العدد الثاني عثر، جزء (0) ديسمبر }
\end{aligned}
$$

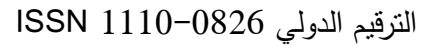




\section{نظرية التخلف الثقافي:}

لقد قدم العالم وليم اوجبرن نموذج في تأكيد التأثثر الاجتماعي اكثر من البيولوجي في

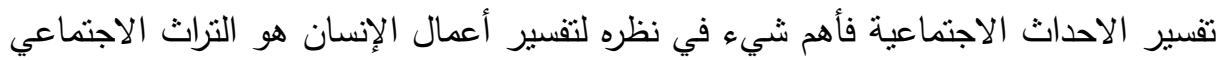

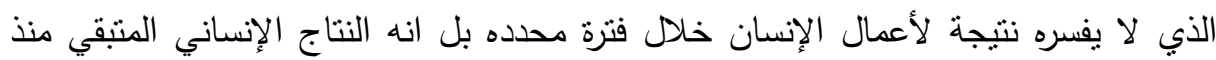

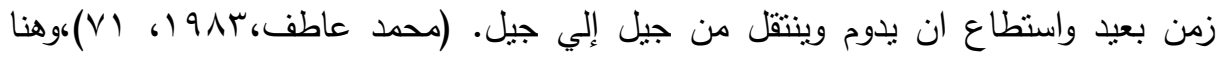

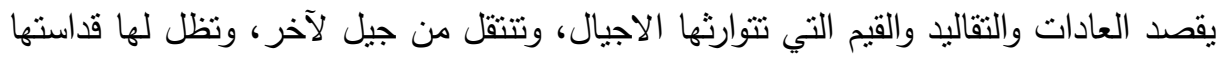
واحترامها بين كل المجتمعات كما انها تختلف من مجتمع لأخر علي حسب طبيعة المجتمع. فالثقافة اللامادية تعني "التراث الاجتماعي، إي ما خلفه شعب معين او حفظه ويشمل

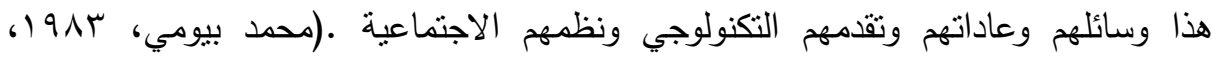

ان التطورات السريعة نسبيا في الجانب المادي مقارنة بالثبات النسبي في الثقافة اللامادية تطرح مشكلة التخلف الثقافي"Cultural Lag"' والذي يشير إلي وضعية تغير عندما يتصارع نوع جديد من السلوك مع القيم التقليدية، حيث تتصف التغيرات في الجانب اللامادي لئي

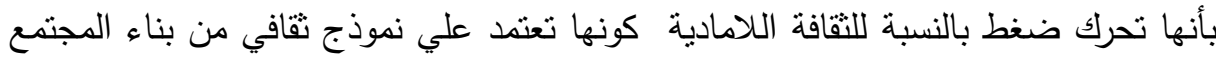

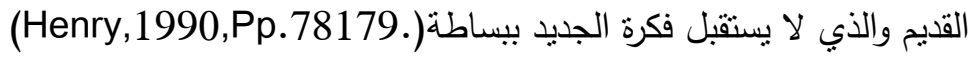
حيث يؤكد فيها أن التغير في الجانب المادي للتقافة يسبق دائما وأبدا التغيير في الجانب

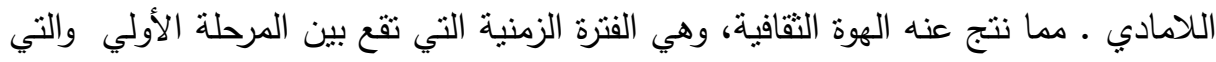
يتم فيها التقدم التكنولوجي والي أن ينتقل إلي المرحلة الثانية التي يتم فيها التغير الاجتماعي . هذه الفترة تتسم ببعض المظاهر التي من بينها الاضطراب والصراع فاستعمال الأدوات الجديدة التهات لا يقتصر علي طريقة استخدامها وصيانتها ـولكنه يستتبع مجموعة من الممارسات والتعديلات

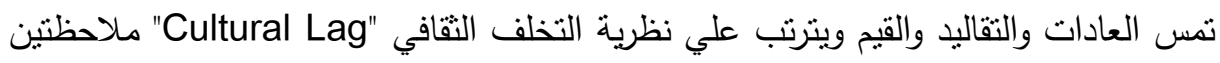

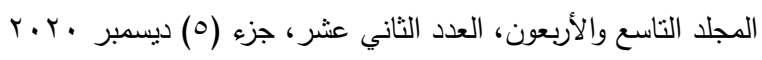

$$
\begin{aligned}
& \text { التزقيم الدولي 0826-1110 }
\end{aligned}
$$




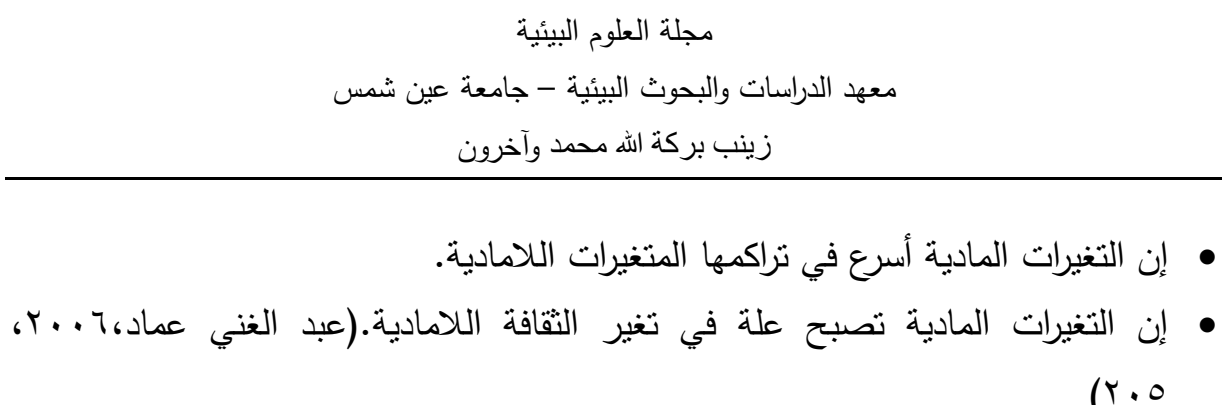

\section{علاقة النظرية بالدراسة الحالية:}

تعد نظرية التخلف النقافي للعالم وليم اوجبرن من النظريات المفسرة للواقع الاجتماعي

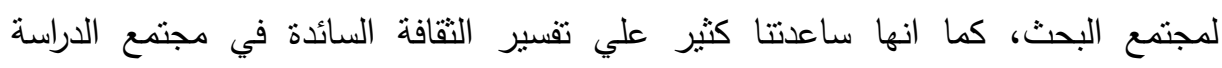

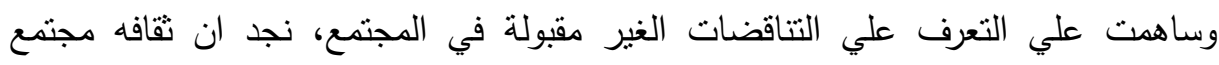
البحث تمثلت في جانبي الثقافة كما ذكر اوجبرن، الجانب الاول وهو الثقافة المعنوية، نجد ان مجتمع البحث وهن العاملات في العمالة غير المنتظمة ينظر اليهم المجتمع نظرة متدنية كما

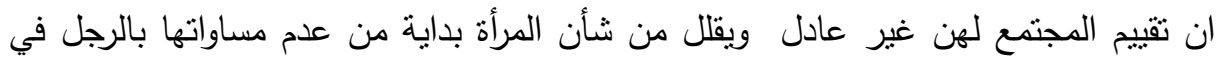

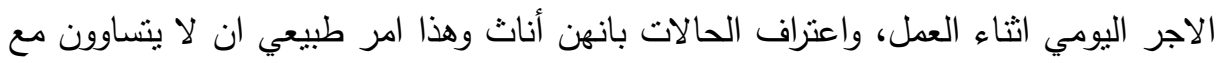

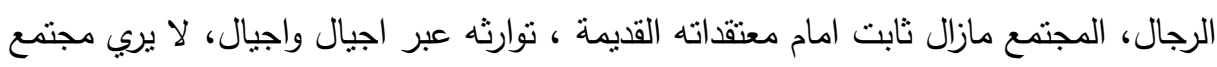
البحث قيمة العلم وتحقيق الذات للمرأة وهذه جميعها امورا معنوية ظلت التقافة المتوارثة ثابته لابنه عندها.

جميع هذه الامور المادية التي أراد افراد المجتمع ان يصبحوا ممن يدعمون استمرارها

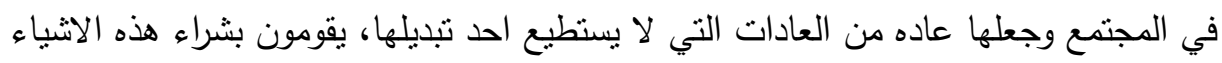

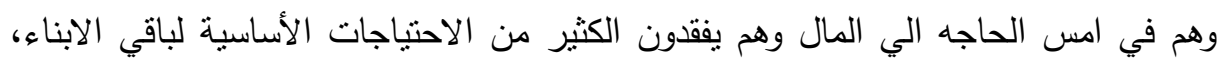

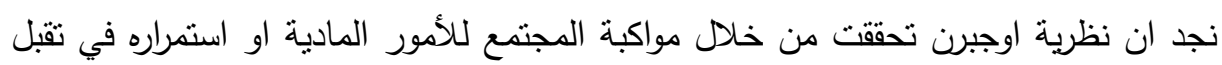

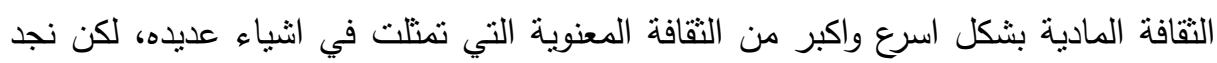
ان التغيرات المادية تتم بشكل اسرع من المعنوية وهذا ما نجده الان هو الفجوة الثقافية بين

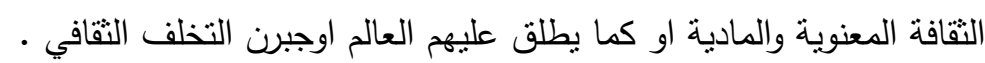

$$
\begin{aligned}
& \text { r.r. المجلد التاسع والأربعون، العدد الثاني عثر، جزء (0) ديسمبر } \\
& \text { الترقيم الدولي 0826- ISSN 1110 }
\end{aligned}
$$




\section{الإجراءايت المنهجية اللهميث}

أولاً: نوع الاراسة: تعد هذه الدراسة من الدراسات الوصفية التحليلية التي تعتمد وصف وتحليل موضوع البحث بالطريقة العلمية التي تعتمد علي استخدام المنهج العلمي. ثنانيا: المنهج المستخدم في الدراسة: استعانة هذه الدراسة باستخدام منهج دراسة الحالة، نظرا لطبيعة مجتمع الدراسة وطبقا للاتي نم استخدام منهج دراسة الحالة: نظرا لطبيعة مجتمع البحث حيث طبقت هذه الدراسة علي العاملات في الاراضي الزراعية من الاناث بأجر يومي وهي عمالة غير منتظمة، وان طبيعة المجتمع يصعب تطبيق الدراسة عليها بشكل مباشر بل ان الامر صعب للغاية، فنجد ان العاملات معظمهن لا يردن التحدث الي ابي شخص غريب او لا يعرفونه بعيد عن بيئة العمل، وانهن لا يثقن في الاخرين

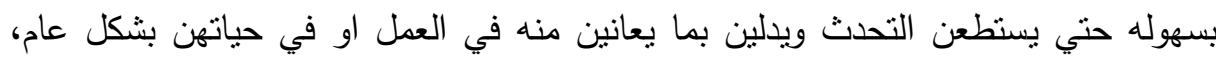

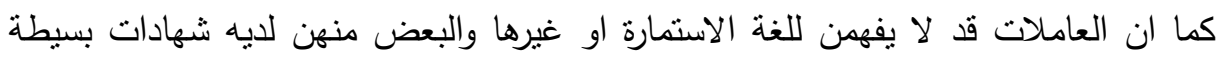

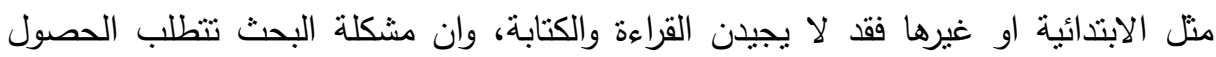
علي الكثير من المعلومات والبيانات الخاصة بهن، كل هذه الاشياء دعتنا الي استخدام منهج

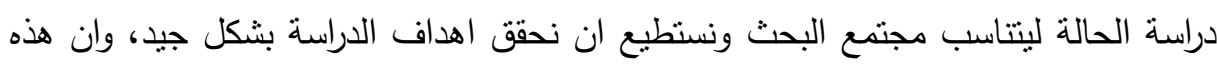

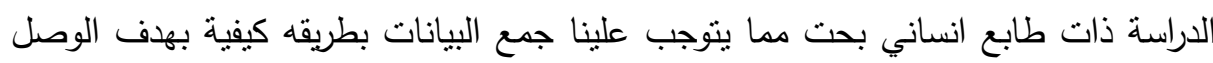
الي الحقيقة .

\section{قضية التعميم في منهج دراسة الحالة:}

تعتبر قضية التعيم من القضايا المثيرة للجدل في دراسات منهج دراسة الحالة، وهناك

الكثير من الآراء المنباينة ولذللك يمكننا ان نلخص هذه الآراء في موققين رئيسيين: الموقف الاول: يرون أنه علي الرغم من اهمية الصدق الداخلي في منهج دراسة الحالة، فإن الصدق الخارجي لا يمثل أهمية كبيرة في دراسات منهج دراسة الحالة، ويشدد اصحاب هذا الرأي علي أن الفرق الرئيسي بين منهج دراسة الحالة والمناهج البحثية الأخري ان الباحثين

$$
\begin{aligned}
& \text { r.r. المجلد التاسع والأربعون، العدد الثاني عثر ، جزء (0) ديسمبر } \\
& \text { الترقيم الدولي 0826-1110 1SSN }
\end{aligned}
$$


المستخدمين لمناهج البحث الآخري يتجاهلون ما تتميز به كل حالة فردية ويسعون إلي الوصول إلي تعاميم متجاوزين الحالات الفردية، يبحثون عن المشترك، بالمقابل ينصب دانئ دراسة

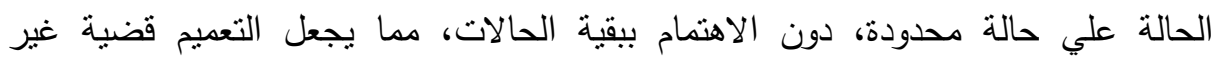
مطروحة في منل هذا النوع من الدراسات. اما الموقف الثاني: فيصر اصحابه علي أن التعميم مسألة مهمة في منهج دراسة الحالة كما هو الحال في بقية مناهج البحث الأخرى، ويري من يتبني هذا الموقف أن نتائج الدراسات

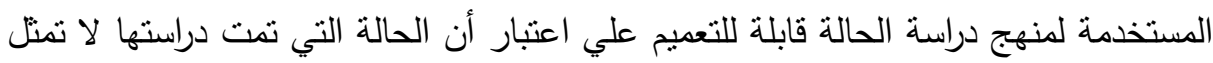

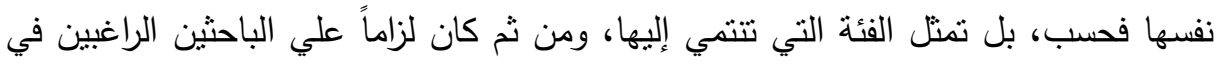

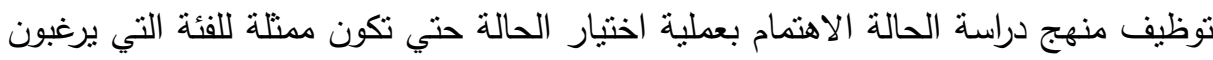

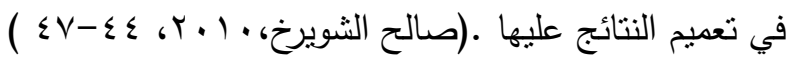

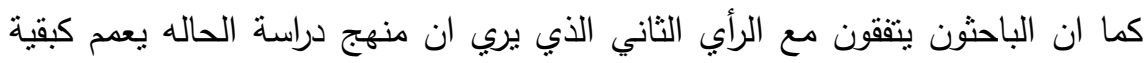

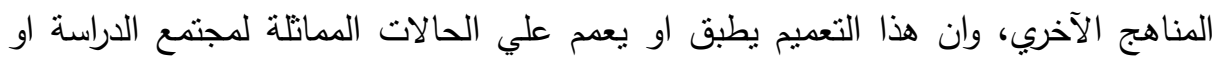
العينة. ثالثاً: الاداة المستخدمة: استخدمت الباحثة اداتي المقابلة المتعققة وكذلك الملاحظة اثثاء الدراسة الحقلية طبقا لما يتتاسب مع مجتمع البحث . كيفية تصميم الأداة أو الاستمارة: تعد اسئلة الدراسة من النساؤلات المفتوحة والبسيطة المستخدمة باللغة العامية لما يتتاسب مع طبيعية مجتمع الدراسة، كما تم الاطلاع علي

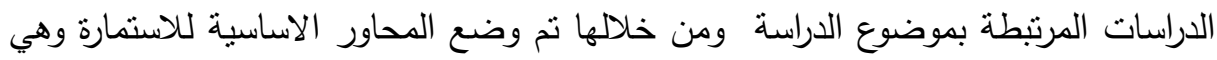

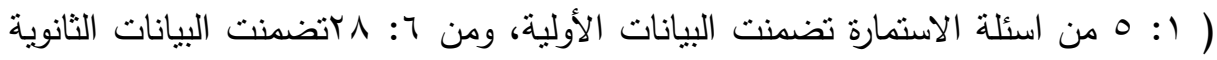
التعلقة بمشكلات الأجور والتحرش الجنسي، ومنه؟ب: هب تضمنت المشكلات المتعلقة

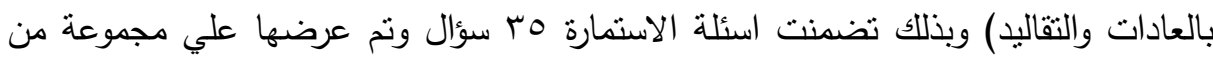
المحكمين، وتمت الموافقة عليها كما نم عمل اختبار للاستمارة علي عدد من المبحوثات

$$
\begin{aligned}
& \text { r.r. المجلد الناسع والأربعون، العدد الثاني عثر، جزء (0) ديسمبر }
\end{aligned}
$$

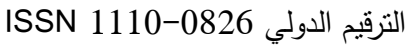


لمعرفة مدي ملائمة وفهم الاسئلة من قبل المبحوثات كما ثم اجراء التعديلات اللازم ثم طبقت

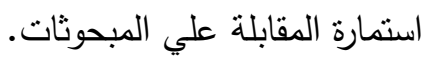

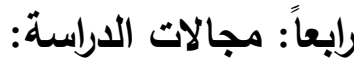

المجال البشري: تم اختيار مجموعه من العاملات في الاراضي الزراعية، وحمل السماد الطبيعي، وقامت الباحثة بتطبيق الاستمارة والدراسة الميدانية عليهن، حيث تمثل عدد المبحوثات في · r حاله يبدأ اعمارهن من 10 عام حتي •r عام تمت دراستهن دراسة مفصلة ومتعمقة مع مراعاة التتوع في السن وسنوات العمل والمستوي العلمي، كما قامت الباحثة باختبار المبحوثات من خلال النزول الي مكان العمل الخاص بهم واختيارهم بشكل

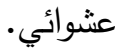
المجال المكاني: طبقت هذه الدراسة علي مجموعة من الإناث العاملات في الاراضي الزراعية في قرية عنيس التابعة لمركز جهينة في محافظة سوهاج، وان المبحوثات يقمن في قري لهي متعددة ومختلفة عن مكان العمل وتابعين لمراكز اخري. المجال الزمني: استغرقت الدراسة الميدانية ثمانية اشهر في جمع الثرين المعلومات والمقابلات المتعقة مع المبحوثات، كما استغرقت الدراسة النظرية والميدانية بوجه عام سنة كامله من

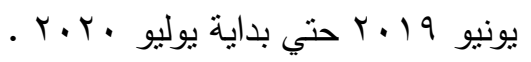
خامساً العينة: طبقت هذه الدراسة علي مجموعة من الإناث العاملات في الاراضي بواتي

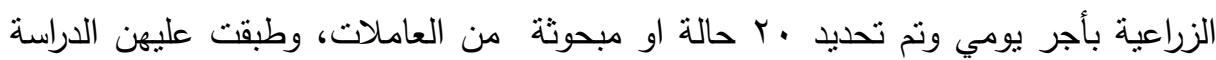

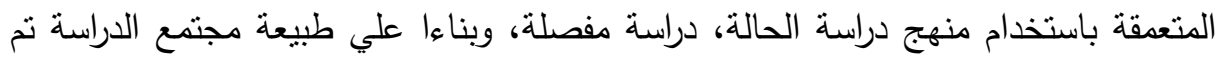

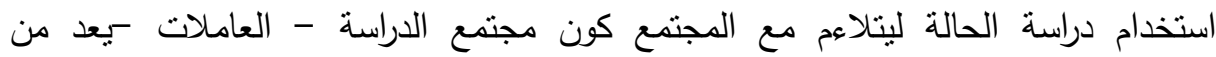
المجمعات المغلقة والتي لا تتحدث بسهولة، ويشعرون بالخوف من كل ما هو خارج اطار العمل، كان لا بد من استخدام منهج كيفي لكي نستفيض في معرف المشكلات المختلفة.

$$
\begin{aligned}
& \text { r.r. المجلد الناسع والأربعون، العدد الثاني عشر، جزء (0) ديسمبر } \\
& \text { الترقيم الدولي 0826-1110 }
\end{aligned}
$$




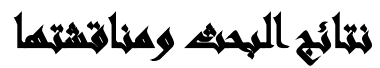

قبل البدء في عرض النتائج تود الباحثة توضيح النتائج المتعلقة بالدراسة والنسب التي تأتي كإجابة علي التساؤلات، ان هذه الدراسة تعد من الدراسات المتعقة والكيفية، كما انها تععقت بدارسة مجتمع البحث والخوض في كافة ما يخص المبحوثات، وان النسب الدارجة في

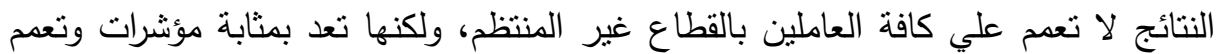
علي الحالات المماثلة لمنل هذه الدراسة.

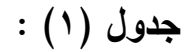

\begin{tabular}{|c|c|c|}
\hline الانحر اف المعياري & الوسط الحسابي & البيانات \\
\hline 3.35 & 19 سنة & اعمار المبحوثات \\
\hline 3.56 & 7 سنو ات & سنو ات العمل \\
\hline 0.37 & 9.4 ساعات & ساعات العمل اليومية \\
\hline 1.32 & 8 أفراد & عدد افراد الاسرة \\
\hline
\end{tabular}

يتبين من الجدول السابق من خلال الوسط الحسابي والانحراف المعياري للعينة، ان مجتمع الدراسة يقل فيه نسب التشتت والانحراف عن الوسط الحسابي، وانه مجتمع متجانس ومتقارب ومن خلال ذلك يمكن لنا التعميم في النتائج التالية ولكن في البداية نود توضيح الاتي: - n

نجد ان اعمار المبحوثات تراوحت من 10 : .ب عام، وهذا يرجع لعدة عوامل منها ان طبيعة العمل نتطلب المجهود البدني العالي والذي لا يستطعن تأديته سوا فئة الثباب نظرا لكون طبيعة العمل يعد من الاعمال الثاقة التي تحتاج الي قوة بدنية وفئة عمرية صغيرة، كما ان طبيعة المجتمع وثقافته وعاداته وتقاليده لا تقبل خروج المرأة المتزوجة للعمل غير المنتظم او العمل باليومية يعد امرا غير لائق وغير مقبول، وان جميع العاملات في الاراضي الزراعية

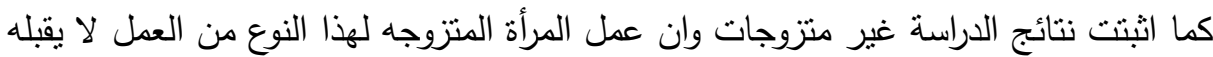

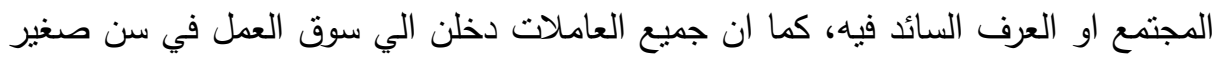
جدا منذ المرحلة الابتدائية، وتظل الفتاة تعمل وتساعد اسرتها ثم تتفق علي نفسها وتفيء

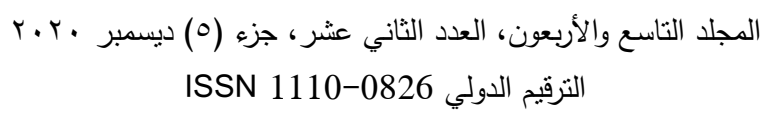


باحتياجاتها وتكمل دراستها لتحصل علي شهادة الدبلوم وتقوم بشراء مستلزمات الزواج وغيرها ثم تتزوج وبعد الزواج لا تدخل الي سوق العمل مره اخري مهما بلغت المعاناة المادية في بيت لئهاء زوجها.

اما المستوي التعليمي للعاملات نجد ان ^ مبحوثات لازلن طالبات، البعض منهن في

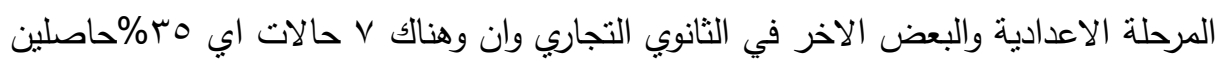

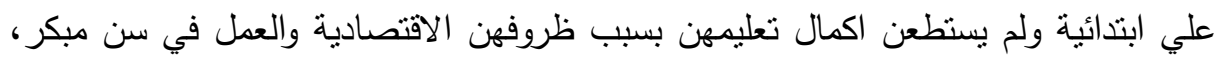
و و حالات حاصلين علي مؤهل متوسط (دبلوم تجارة). كما ان نتيجة لدراسة الميدانية نجد ان عدد اسر العاملات كبير للغاية يتراوح ما بين 7:11 الفرد في الأسرة وان منوسط عدد افراد الأسرة يصل الي 9 افراد. أولاً: النتيجة المتعلقة بالإجابة علي التساؤل الثاني: هل تتعرض العانية العاملات للتحرش الجنسي أو اللفظي اثناء العمل ؟ أوله -جاءت اجابة و 19 حالة ابي نسبة 90 \% من العاملات اكدن علي انهن يتعرضن للتحرش اللفظي بألفاظ خارجه اثثاء العمل. وهذا ما اكدته احدي الحالات قائله:" بصي في ناس قليلة الادب ويقولوا كلام وحش

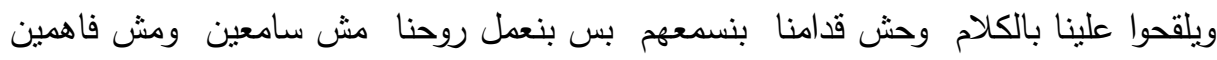
بس احنا مانخلهم ياخدوا بالهم يقعدوا يحكوا عن الجواز وكده وتفاصيل ويقعدوا يحكوا

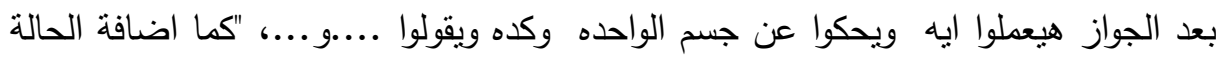
الثانية قائله:" كثير بصي لو شغاله مع ولد بييقي عايز يتلفق فيكي (بنلزق) ويقعد ينوع في طريقة كلامه، ولما اجي احكي معاه يعني لو متجوز بحكيلك في المعانشره بينه وبين مراته،

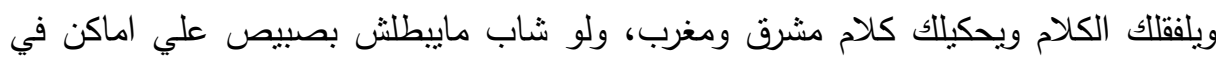

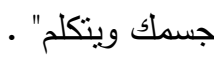
- بينما جاءت اجابة • احالات إزاء التحرش الجسدي او الجنسي بنسبة .0\% بأنهم

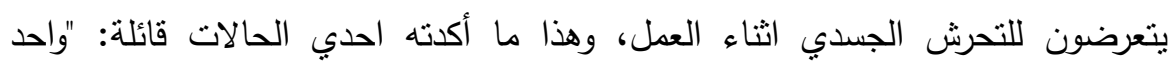
258

$$
\begin{aligned}
& \text { r.r. . المجلد التاسع والأربعون، العدد الثاني عثر ، جزء (0) ديسمبر } \\
& \text { الترقيم الدولي 0826-1110 }
\end{aligned}
$$


اتعرضلي سبته لما قرب عليا خالص وكان قرب يغتصبني، قرب عليا جوي وانا واقفه اول ما ...(اقترب بشده) طلعت المطوي وضربته في جانبه اخد بr غرزه ".وقالت الاخري :

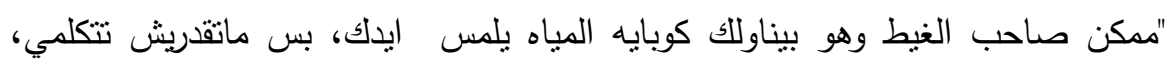
هيقولك في ايه انا ماقصدش، بس انا عارفه انه قاصد".

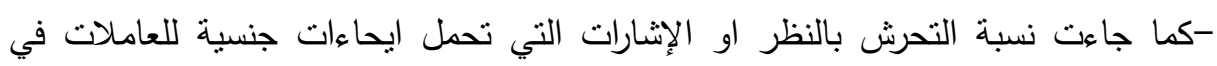
العمالة غير المنتظمة بنسبة • ؛ \% من مجتمع البحث يتعرضن لهذا النوع من التحرش.

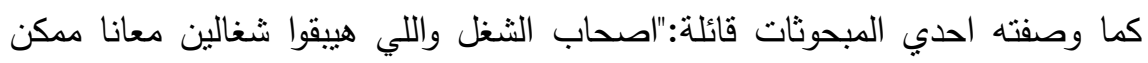
يعمل حركات كده قدامك ماتعجبكيش، ممكن يغمزلك بعينه او يشاورللك علي حاجه وحشه او

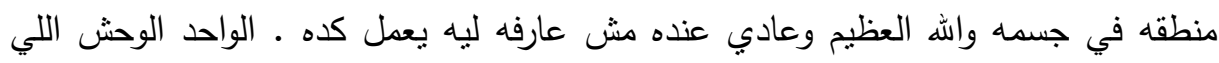
بييص بصات وحشه مش بعدل بعني ييص علي منطقه صدري وكده ومن ورا ويقول كلام

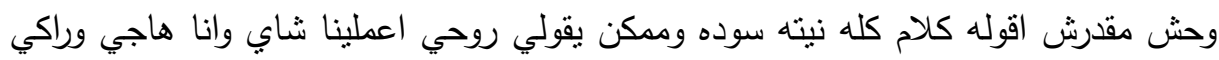
وبيكون فاكرني بنت مش كويسه في بنات ممكن تعمل كده وكمان الشغل في الجبل صعب لهب ومابرضاش انشرب الثابي عندهم لانهم بيحطوا في الثاي برشام تامول واحيانا مخدر مدكن يحط المخدر ويعمل حاجات مش كويسه". - كما ان ردة فعل الإناث المتعرضين للتحرش الجنسي إزاء التحرش التجاهل والسكوت اتجاه

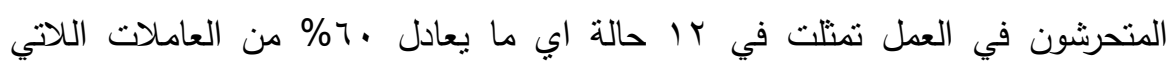

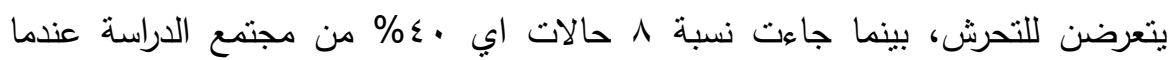
يتعرضون للتحرش يقمن بالرد والردع اتجاه المتحرشين. كما قالت احدي الحالات :"اي واحد بيعمل معايا اي حاجة وحشة هغلط فيه واشتمده واقل من قيمته قدامنا كلنا"،وقالت الاخري :"ما اتكسفش هزعق علي طول واغلط".

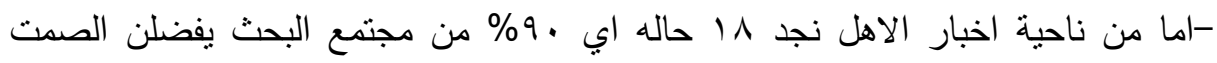
وعدم التحدث امام الاهل بأي شيء يحدث لهمن في العمل خوفا من ان يقمن الاهل

$$
\text { بمنعهن من الخروج الي العمل. }
$$

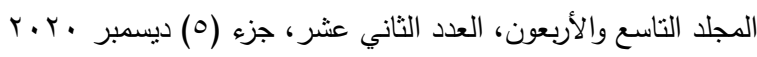

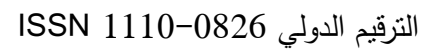


وهذا ما اكدته إجابات الحالات فيما يلي:" لا اي حاجه بتحصل معايا بره البيت او في

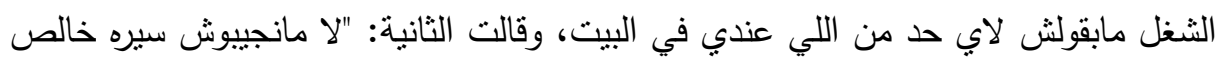

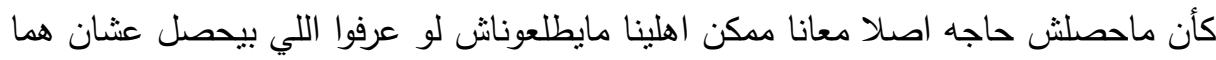
في البيت مش عارفين ايه اللي بيحصل اصلا، هيقوللنا ماتطلعوش وهيخافوا علينا.

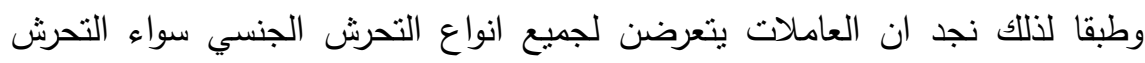
اللفظي او الجسدي او بالنظر وهذا شيء منوقع نظرا لطبيعة العمل غير المنتظم الذي يخلو

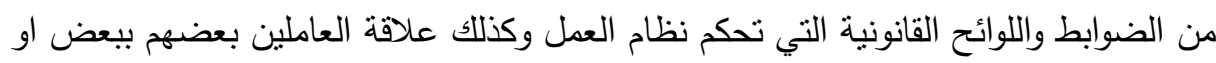

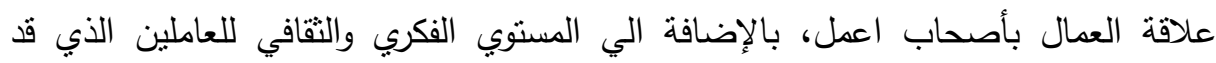

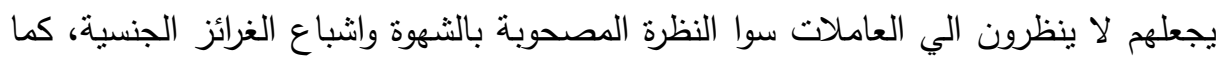

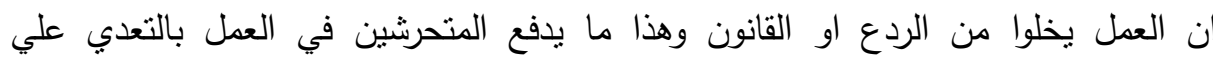

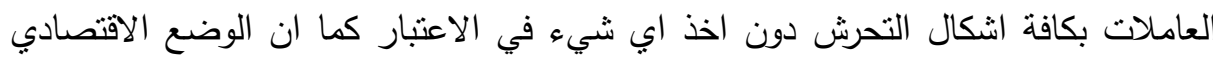

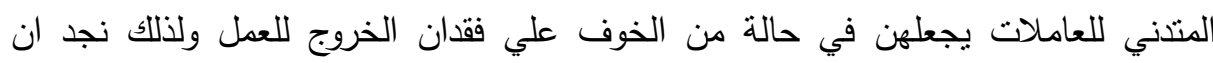
معظمهن يفلن الصمت والتجاهل، وهذا ما جعل الرجال يتمادون في اعتداءاتهم علي الإناث لروئتهم ضعفهن وقلة حيلتهن إزاءهم.

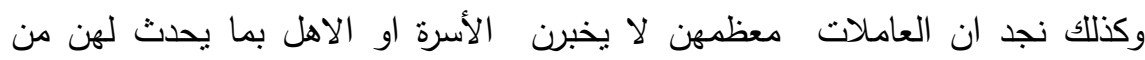

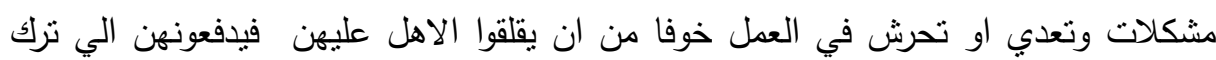
العمل والمكوث في المنزل، علي الرغم من ان العاملات يعطن من اجل الانفاق علي اسرهن

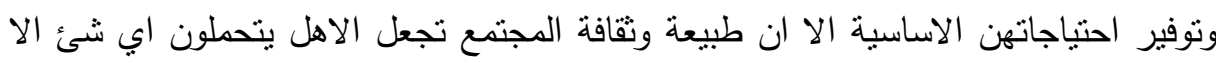

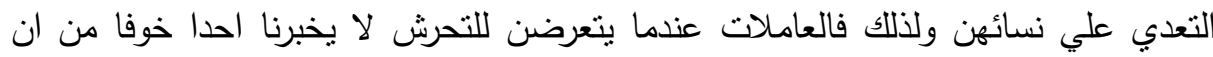

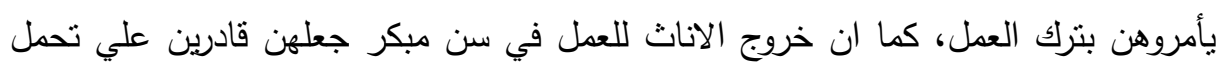

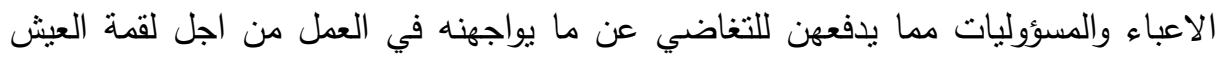

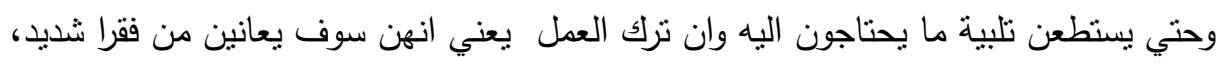

$$
\begin{aligned}
& \text { r.r. المجلد التاسع والأربعون، العدد الثاني عشر، جزء (0) ديسمبر } \\
& \text { الترقيم الدولي 0826-1110 }
\end{aligned}
$$


ولم يستطيعوا تلبية حاجتهن لمكوثهن في المنزل ولذلك فهم يفضلن عدم البوح بما يحدث

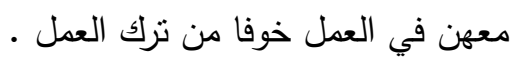

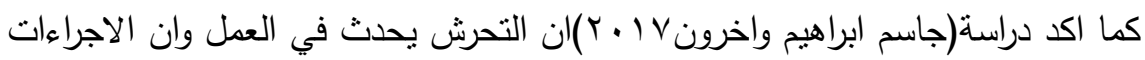
التي تتخذها العاملة عند النعرض للتحرش صفر ل لكونهن يخشون الفضيحة ورد الفعل من قبل

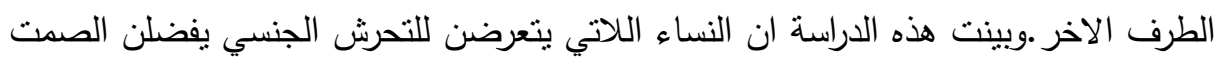

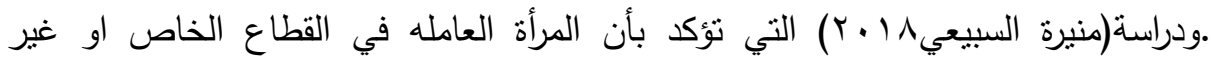
الرسمي تتعرض للتحرش الجنسي من قبل الزبائن.

لذلك نجد ان النظرية البنائية الوظيفية من النظريات المفسرة لهذه المشكلة كونها نري انتي ان

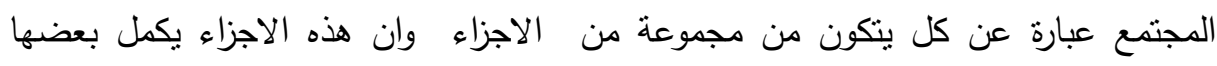

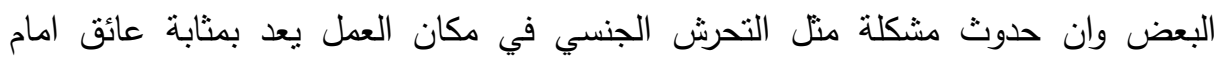
العاملات للقيام بعملهن بشكل افضل مما قد يؤدي الي حدوث خلل والتسبب في مشكلات تؤدي الي خلل في المجتمع بأكمله.

ثانياً: النتيجة المتعلقة بالإجابة علي التساؤل الثالث: هل هناك مشكلات متعلقة بالأجور؟

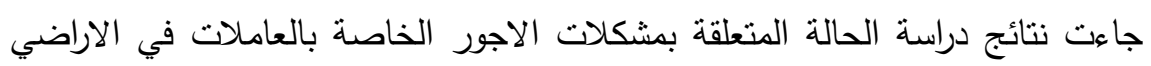
الزراعية كعمل غير منتظم متمثلة في الاتي:

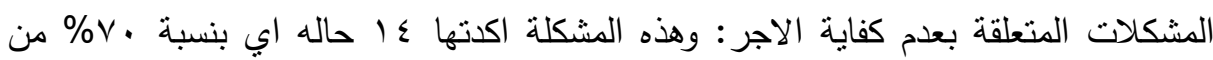
العاملات يعد الاجر اليومي الذي يتقاضينه غير كافي لنوفير احتياجاتهن وكذللك احتياجات اسرتهن الاساسية .

وهذا ما أكدته احدي الحلات قائلة: "لازم احوش اجر يومين تلاته عشان اقدر انشتري حاجة محتاجيها انا واهلي في البيت لما احوش اجر يومين تلاته هجيب اللي انا محتاجاه لكن الاجر اليومي ممكن تحودي(تذهبي به) بيه علي الدكان تجيبي بيها حلاوه وحاجات، هي مش اهن

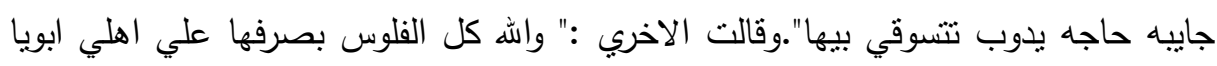
وامي ومافيش حاجه مكفيه" .

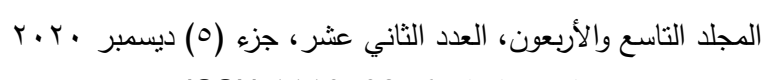
261

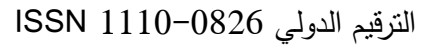


كما ان هناك ب حالات قالوا بأنهم يعطون اجرهم للاهل والاسره ولا يأخذون منه شيئًاً

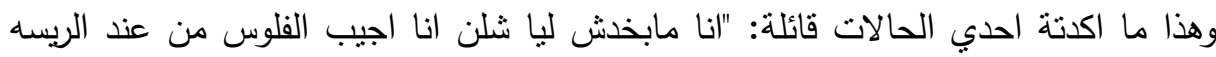

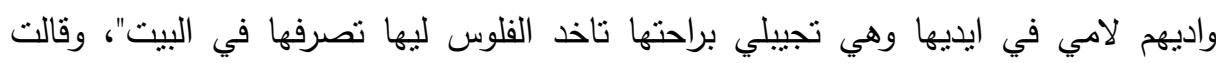

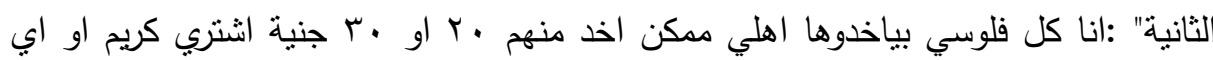

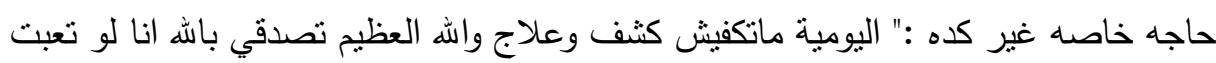

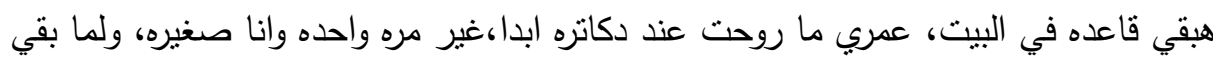

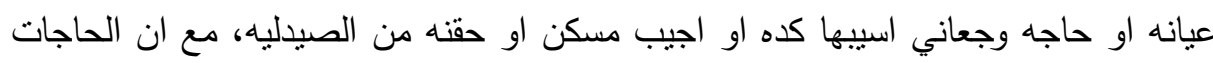

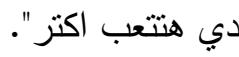

وهذا يعني أن العاملات يعطون للأهل الآخر اليومي ولا يأخذون من شيئا ، من أجل

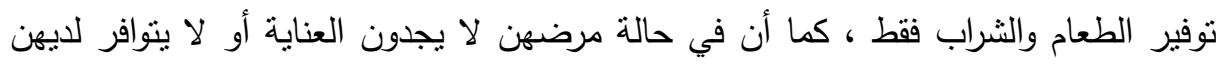

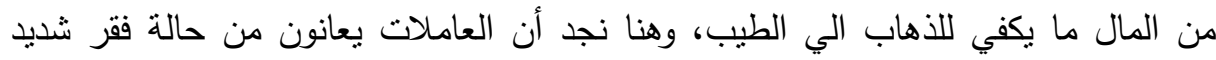
للغاية ، فقد حرموا من التعليم ومن الطفولة وكذللك تدهور في الحالة الصحية ولا يتوافر لهم

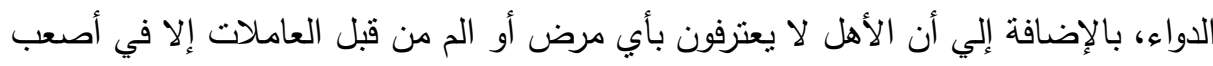

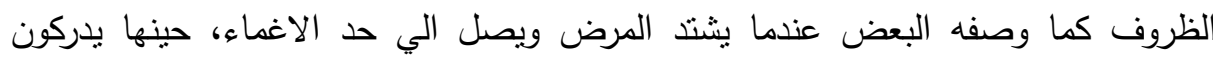
الأهل ان الفتاه في امس الحاجه للعلاج. كما ان عدم مساواة الاجر اليومي بالمجهود الذي بذلنه العاملات اكدته 17 حاله منهن اي بنسبة . ^^\% من مجتمع الدراسة. أكدن علي ان العاملات من الإناث في العمالة غير المنتظمة يبذلن قصاري جهدهن في العمل وان العائد المادي غير مجزي لهن بالإضافة الي ان طبيعة العمل يعد من الاعمال

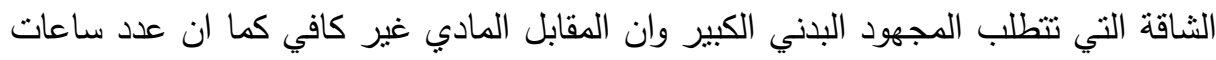
العمل لا يقل عن 9 ساعات منواصلة من الجهد والتعب وهذا ما اكدته احدي الحالات قائلة:"الاجر لا مايساويش بس في ناس غلبانه فقيره ، العشره جنيه محتاجاها في الزمن ده،

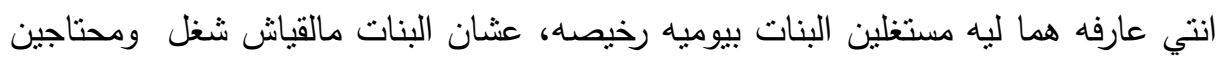
262

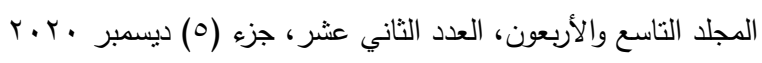

$$
\begin{aligned}
& \text { التزقيم الدولي 0826-1110 }
\end{aligned}
$$


واهلينا علي قدهم واله احنا حتتنا دي فيها ناس فقره جوي والبنات كلها هتتتغل" . كما جاءت

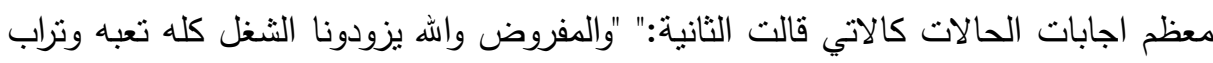

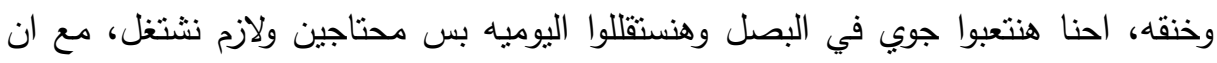

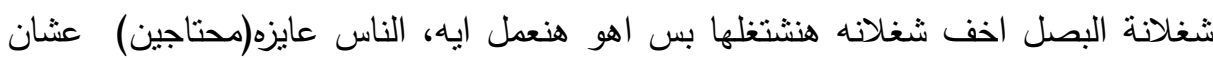
كده هنشتغل" . وطبقا لما جاء من نتائج من عدم كفاية الاجر وقلته فالعاملات في العمل غير

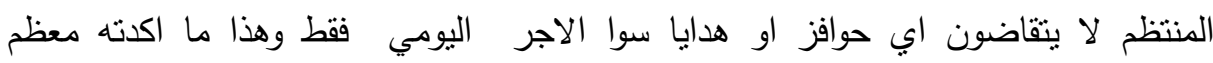

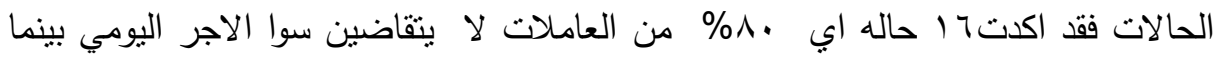
قال البعض بانهم قد يأخذون زيادات قليله جدا ونادرا ما يعطونهم اصحاب العمل هذه الزيادات

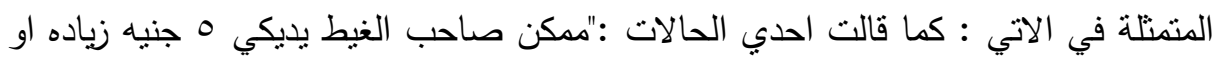

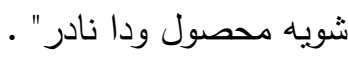
تنين لنا من خلال النتائج ان معظم العاملات يقمن بالإنفاق علي انفسهن واسرهن

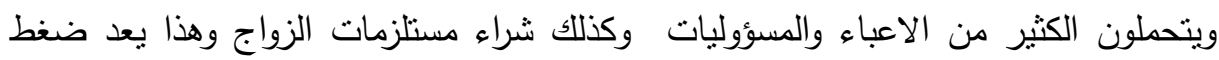
كبيرا عليهن وان الاجر اليوم لا يكفي لذلك، كما ان الاجر غير ثابت ويختلف من عمل الي

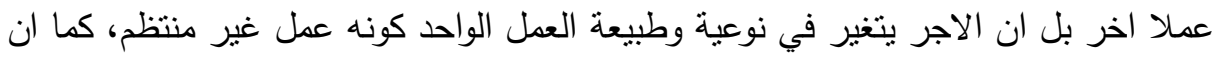
الاجر لا يكفي في حالة المرض او توفير العلاج وان معظم الحالات بعانين من امراض

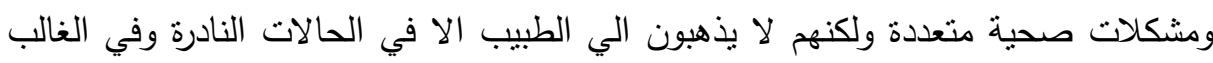
يذهبون الي المستشفيات الحكومية والتي في الغالب قد لا يتلقون العناية الجيدة، كما ان الاهل لا يهتمون بالعاملات عند ما يمرضن وان الاجر اليومي ينفق علي الاحتباجات الاساسية بل انه لا يكفيها . الحكن كما اكدن جميع المبحوثات بانهن يتقاضين نصف ما يتقاضاه الرجل وهذا ما اكدن عليه .r حاله اي بنسبة ... (1\% من مجتمع الدراسة بأن هناللك تقرقه عالية في الاجور

$$
\text { وتحيز للرجل ضد المرأة. }
$$

$$
\begin{aligned}
& \text { r.r. المجلد التاسع والأربعون، العدد الثاني عشر، جزء (0) ديسمبر } \\
& \text { التزقيم الدولي 0826-1110 الإنعند }
\end{aligned}
$$




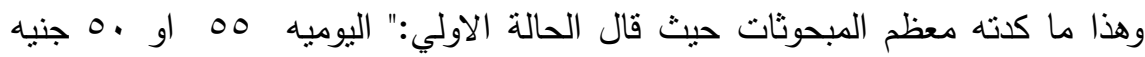

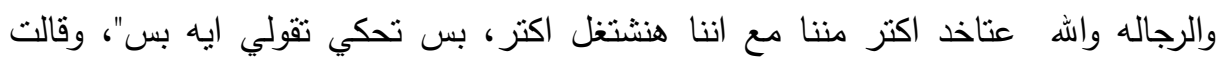

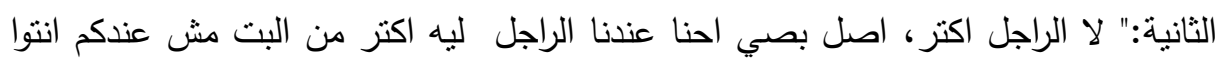

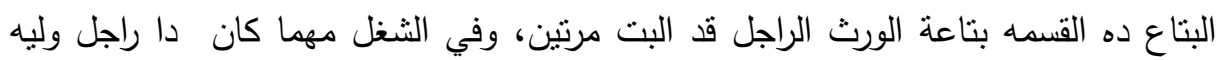

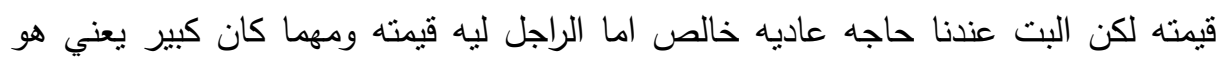

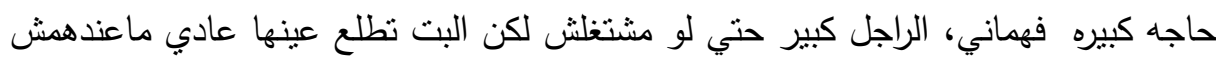
رحمه علينا.

حيث توصلت نتائج الدراسة من خلال إجابات المبحوثات بانهن يتقاضين نصف اجر الرجل مع تأكيد المبحوثات بأن طبيعة العمل واحده، بل ان العاملات من الإناث يبذلن

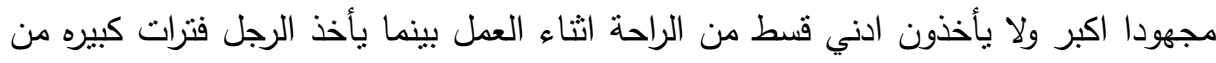

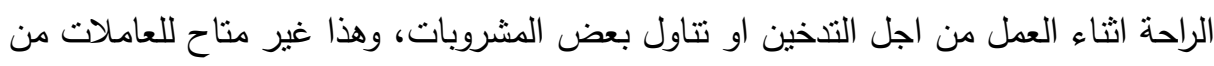

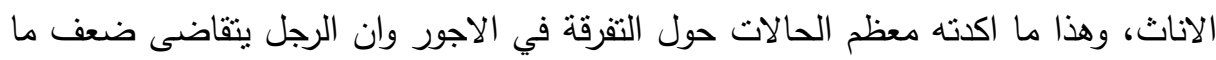

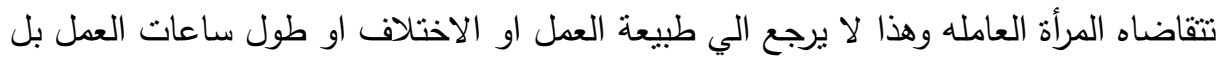
ان العاملات جميعا اكدن علي ان ساعات العمل واحده وكذلك طبيعة العمل واحده وان كان هناك اختلاف في طبيعة العمل فهو اختلاف بسيط. وان السبب الاساسي في التفرقة برجع الي النوع فقط كونه رجل وكونها انثي، وهذا برجع

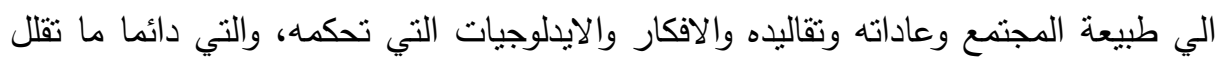

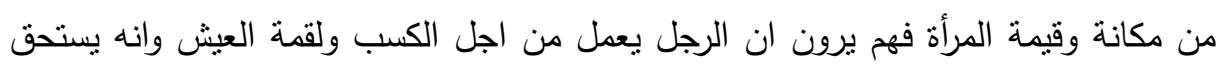

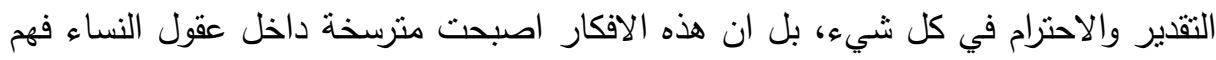

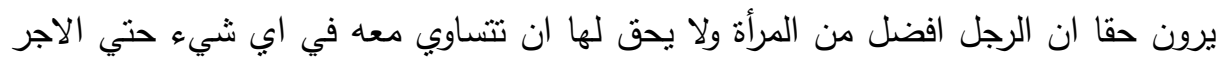

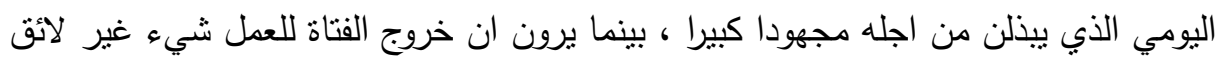

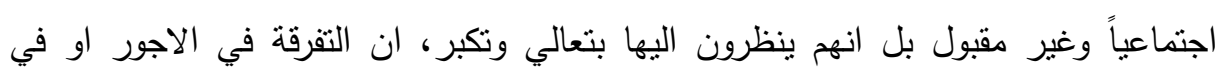

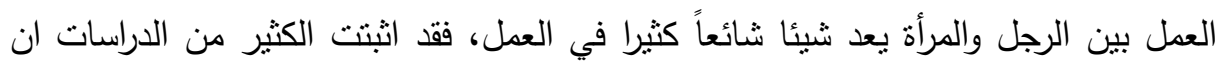
264

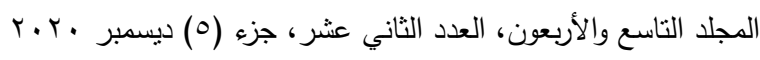

$$
\begin{aligned}
& \text { الترقيم الدولي 0826-1110 1SSN }
\end{aligned}
$$


هناك تمييز بين المرأة العاملة والرجل من حيث الاجور والترقيات والحوافز وغير ذلك الكثثر

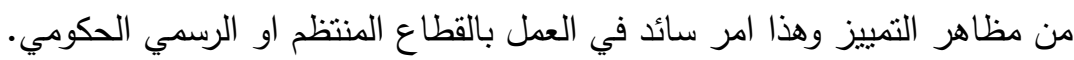

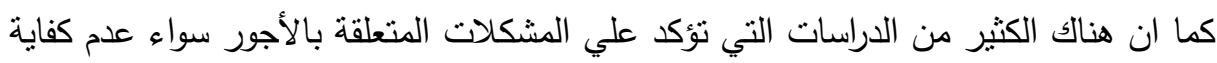
الدخل للعمالة غير المنتظمة او مشكلة التحيز ضد المرأة في الاجور، ومنها الدراسات الاتية:

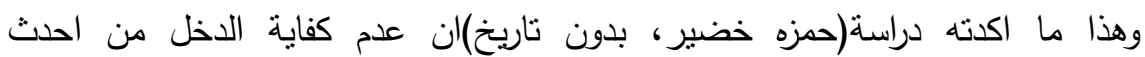

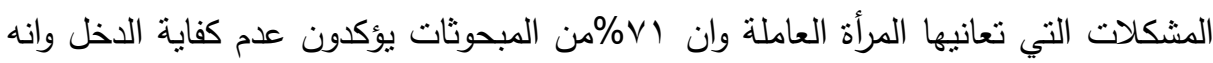

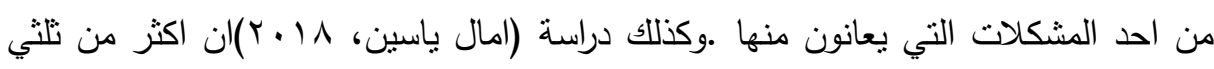

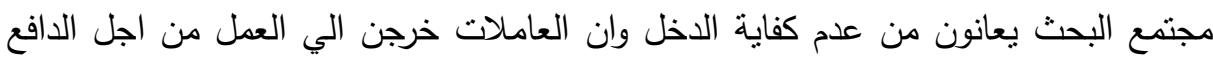

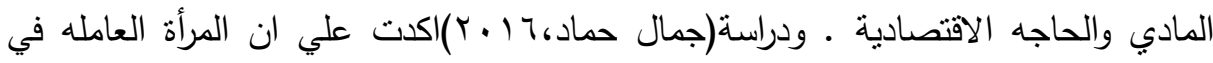
الريف في القطاع غير الرسمي تتعرض للتمييز بينها وبين الرجل في الاجر، ممن يعملون

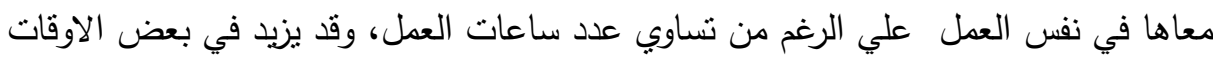

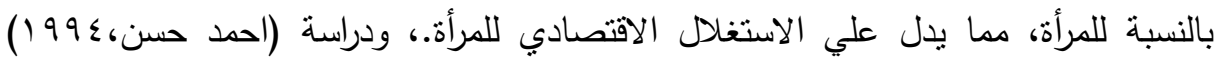

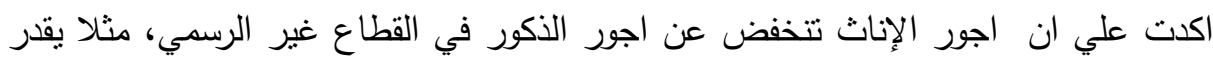

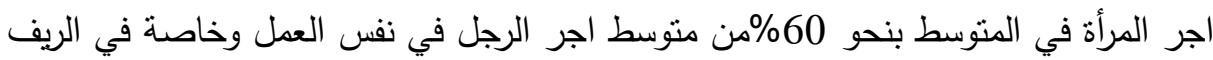

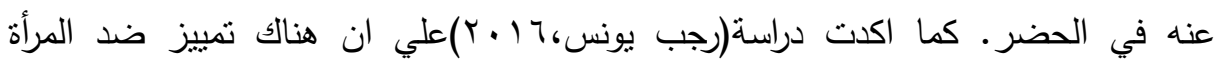
العاملة في قطاع البنرول في الاجر حيث تثتاضي أجراً اقل من اجر الرجل. كما أن هناك نظريات علمية تفسر هذه المشكلة وهي النظرية النسوية التي تتاقش القضايا التي تحمل شكلا من اشكال التحيز والتمييز ضد المرأة في العمل او في الاجور وكذلك الوقوف ضد القهر الذي تتعرض له المرأة في المجتمع والنظرة المتدنية لها، فتري هذه النظرية انه لا بد من مساواة المرأة بالرجل وترفض التحيز ضدها او التقليل من شأنها، كما انها تسعي الي محاربة الافكار التي تؤيد الرجل وتدعمه ضد المرأة وتبحث عن المساواة بينهما

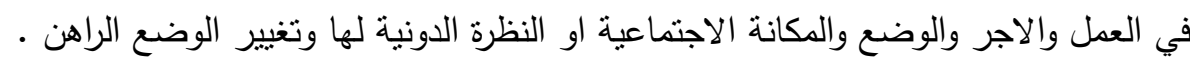

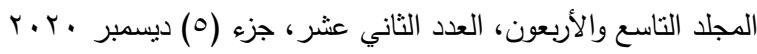

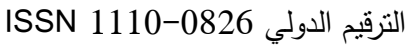


ثالثاً: النتيجة المتعلقة بالإجابة علي التساؤل الرابع: ماهي العادات والتقاليد السائدة في المجتمع التي تؤثثر بشكل سلبي علي مجتمع البحث؟ بالابه عليه

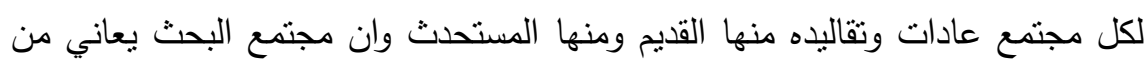
العادات والتقاليد التي انتشرت بكثره في الآونة الاخير وهي شراء الكثثر من مستلزمات الزواج

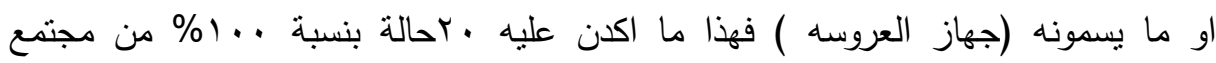

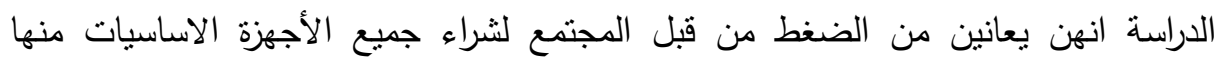
والكماليات وانهن يعملن من اجل توفير الاحتياجات الأساسية لهن ولأسرهن وهذا ما من اكنداء

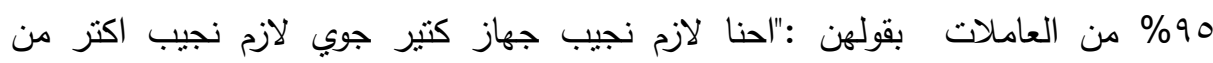
بعض"'"وقالت الاخري." اللي بتطلع تتجوز لازم تكون زايده عن اختها اللي قبلها وعن الناس لاس لهاب

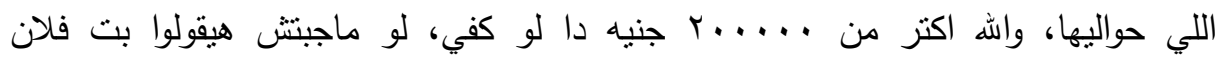

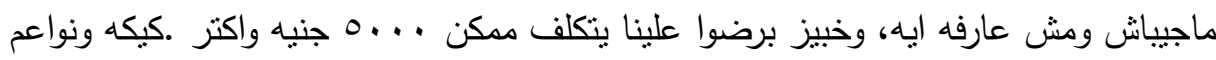

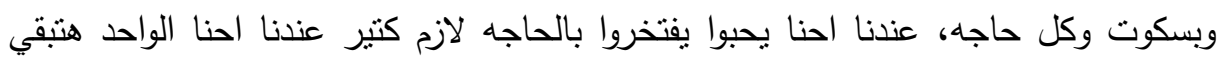

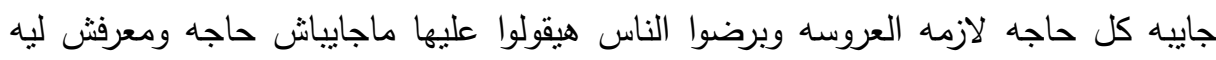
عندنا هيعملوا كده، والي تجيب علي قدها هتتفضح عندنا واله العظيم ويقولوا عليها دالها ابوها ماعندوش ومامعاهاش، وابوها ماجبش لبنته حاجه زي البنات، وكمان حماتها وسلايفها، تقعد

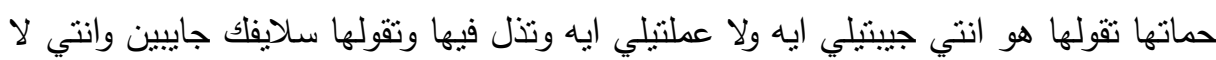
ماجيباش حاجه هي زايده عنك حاجه، لازم الواحد تجيب زي مابيجيبوا وزياده كمان، دا لسه

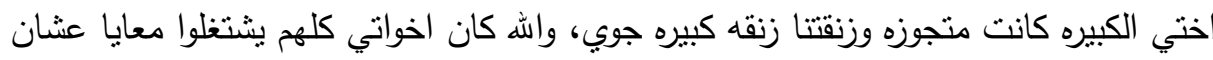
نطلعوها ونخلصوا حاجتها واتزنقنا برضوا ورحنا سحبنا قرض من البنك وجبناه، ولما كنا ناخد

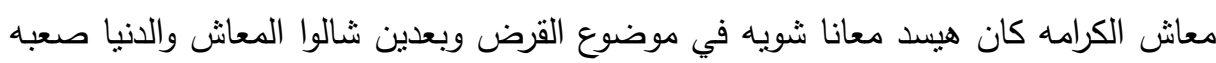
جوي، ومرار الاقساط ". ومما سبق ذكره من قبل المبحوثات يتضح لنا ان العاملات يعانين من العادات المرتبطة

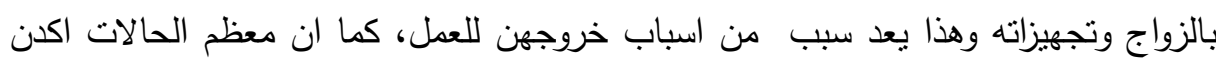
266

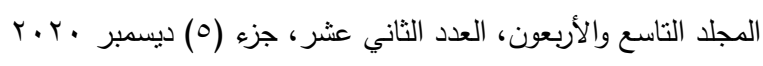

$$
\begin{aligned}
& \text { الترقيم الدولي 0826-1110 }
\end{aligned}
$$


علي ان شراء جميع مستلزمات الزواج وبكثرة امرا ضروريا لا غني عنه وغير مقبول اجتماعيا

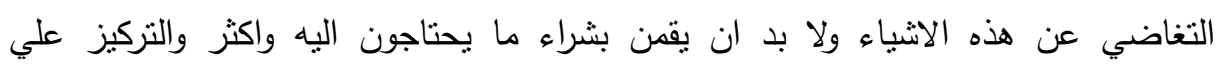

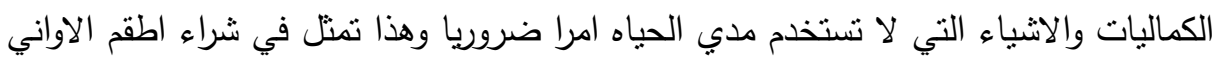
والمفروشات باهظة الثمن والنيش ومستلزماته والكثير من الاثشياء التي تعد من الكماليات

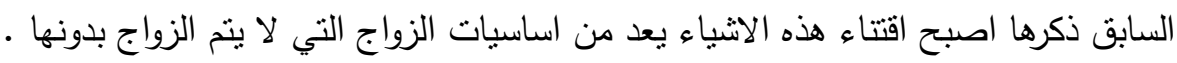

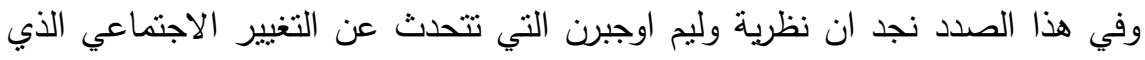

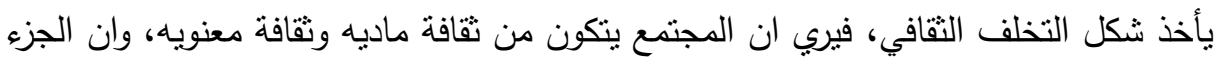

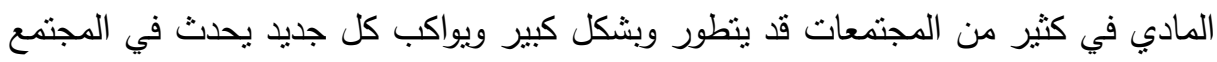

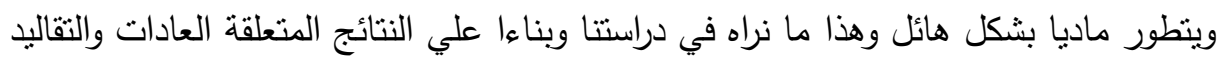
نجد ان مجتمع الدراسة يواكب كل جديد في الامور المادية المتعلقة بشراء تجهيزات الزواج وغيرها نجدهم يقومون بشراء الأجهزة الكهربائية بشكل مضاعف ابد الي من كل نوع اثثين وثلاثة،

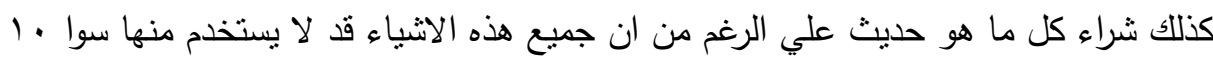

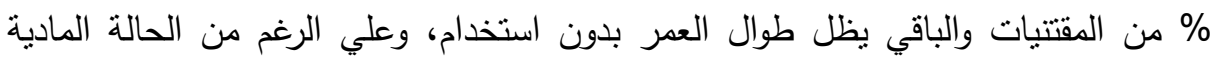

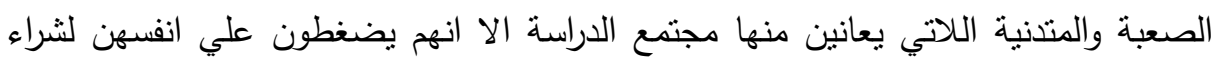
هذه الاشياء لمواكبة التغيرات المادية التي تحدث، وعلي صعيد التقافة المعنوية المتعلقة بالأفكار والقيم نجدهم ذو فكر متحجر للغاية، يفكرون كما كان يفكر العرب من اكثر من

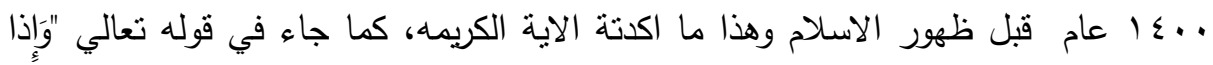

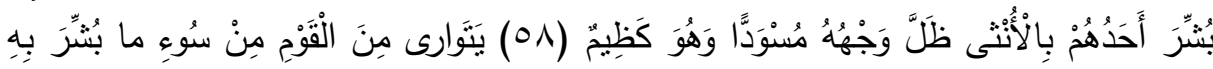

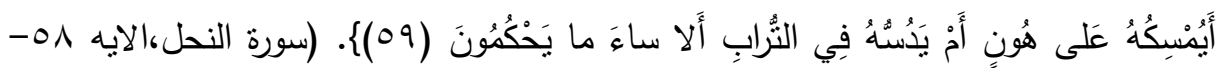

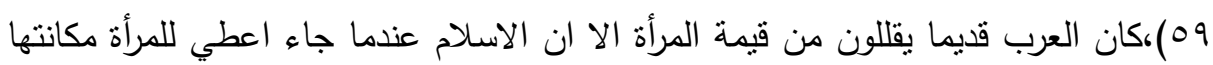
وقيمتها الحقيقية، ولكنا في الوقت الحالي نجد ان مجتمع الدراسة يقلل من قيمة ومكانة المرأة

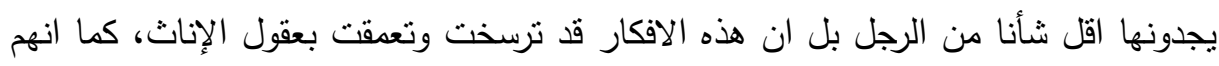

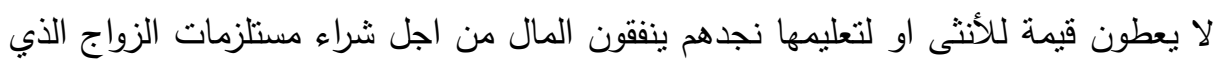

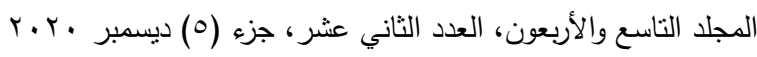

$$
\begin{aligned}
& \text { الترقيم الدولي 0826- ISSN 1110 جنان }
\end{aligned}
$$


قد يتكلف اكثر من ... . . . جنيه وهذا ما اكدنه معظم الحالات، ولا يعطون للفتاة قدر من

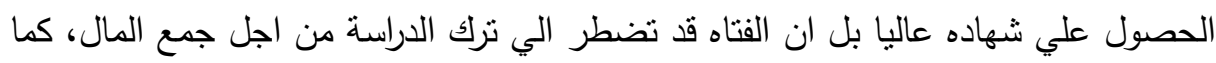

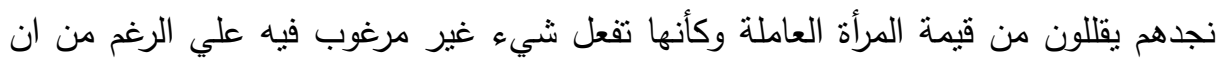

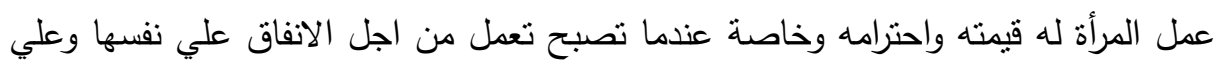
اسرتها هنا تكمن عظمة ومكانة المرأة، الا ان المجتمع نظرا لعاداته وتقاليده يقلل من قدرها. نجد ان نظرية وليم اوجبرن فسرة هذا الاختلاف الكبير بين الثقافتين المادية والمعنوية وخاصة عندما نظل الثقافة المادية في التقدم ومواكبة الحاضر وتظل الثناف الثقافة المعنوية ثابت عند حد معين من الزمن، يعد كما اسمها وليم اجبرن التخلف التقافي او الفجوة التقافية او الهو الثقافية، وهو التتاقض والتخلف الذي يعاني منه مجتمع الدراسة. تعد نظرية التخلف الثقافي

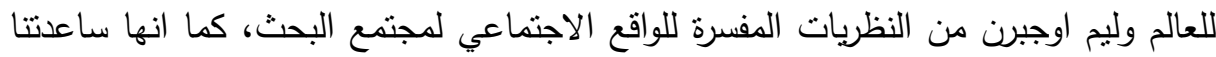
كثير علي تفسير الثقافة السائدة في مجتمع الدراسة وساهمت علي التعرف علي النتاقضات

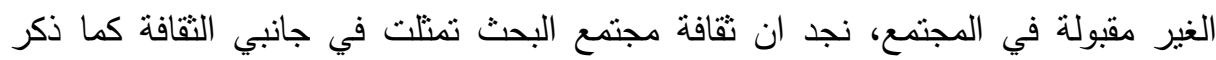
اوجبرن، الجانب الاول وهو الثقافة المعنوية، نجد ان مجتمع البحث وهن العاملات في العمالة

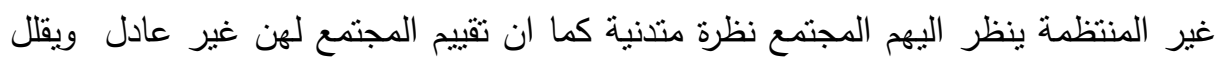

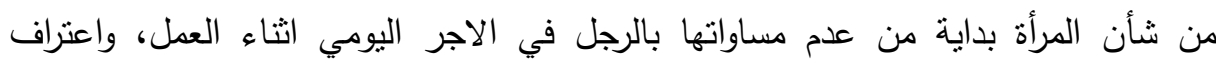
الحالات بانهن أناث وهذا امر طبيعي ان لا بتساوون مع الرجال، كون الرجال اعلي شأنا

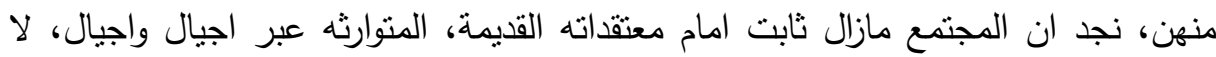

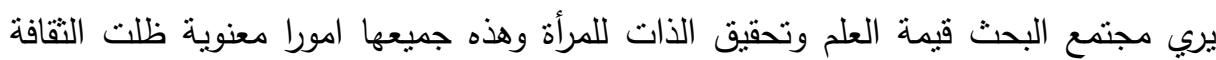
المنوارثة ثابته عندها، وعندما نأتي الي الجانب الثاني من الثقافة وهو الجانب المادي كما ذكره

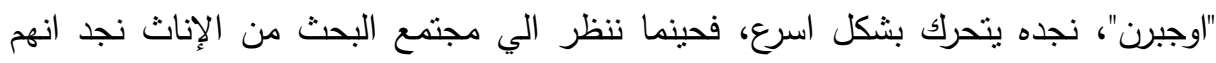

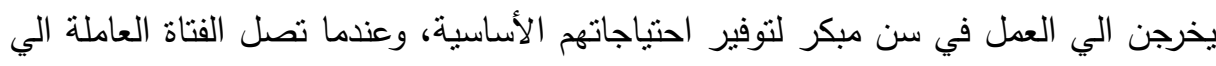

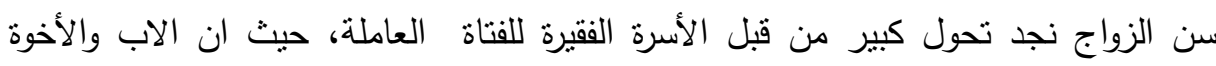

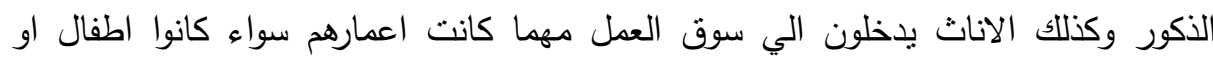
268

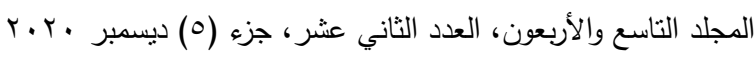

$$
\begin{aligned}
& \text { الترقيم الدولي 0826-1110 }
\end{aligned}
$$


شبابا، يعملون ليل ونهارا من اجل شراء مستلزمات الزواج للفتاة، من اجل شراء جميع

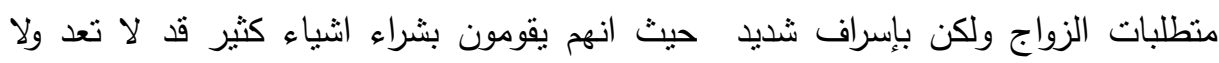

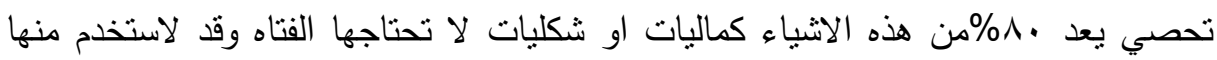
شيء طوال حياتها،، ولكن يتم شرائها من أجل مواكبة التغيرات السائدة في المجتمع، التي لأني

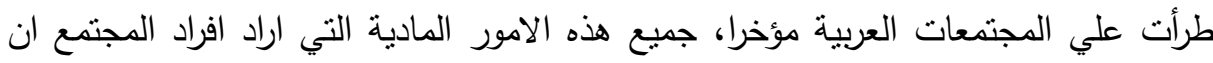

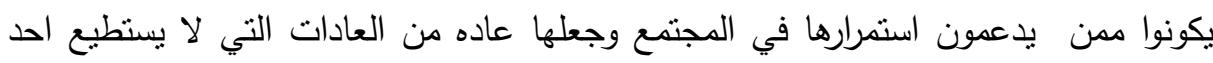
تنديلها، يقومون بشراء هذه الاثياء وهم في امس الحاجه الي المال وهم يفقدون الكثير من

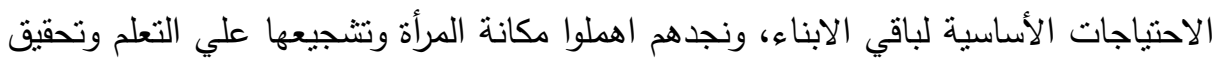

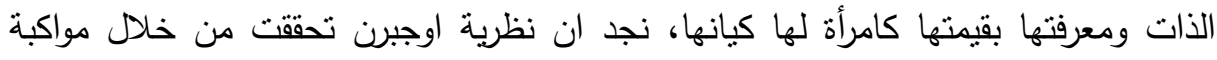

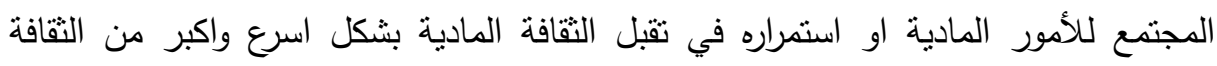

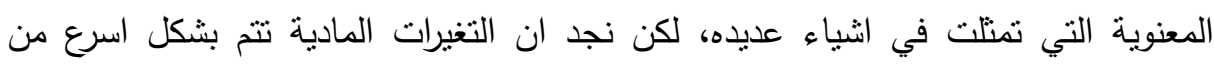

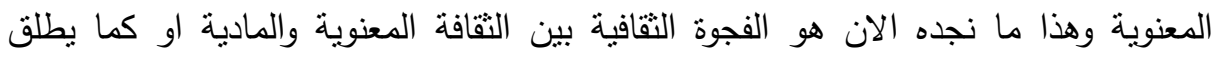
عليهم العالم اوجبرن التخلف التقافي .

\section{zall}

(سورة النحل،الايه ميد-09)

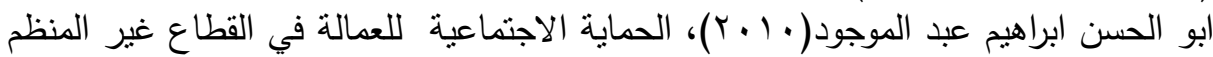

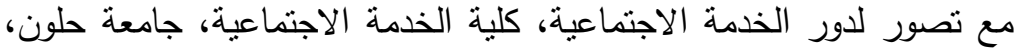

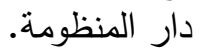

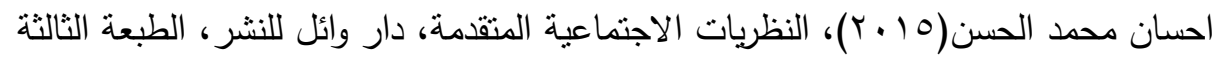

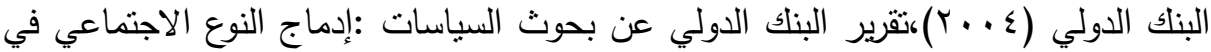

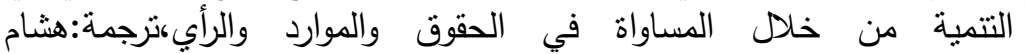

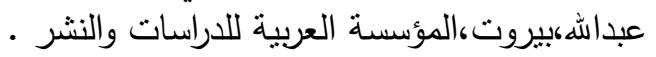

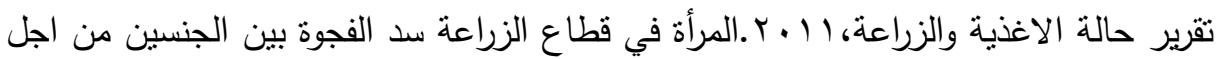

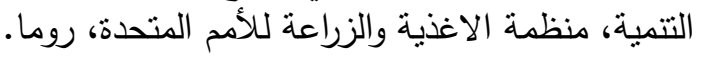

$$
\begin{aligned}
& \text { r.r. المجلد التاسع والأربعون، العدد الثاني عثر، جزء (0) ديسمبر }
\end{aligned}
$$

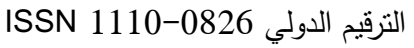




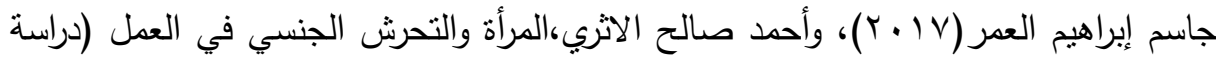

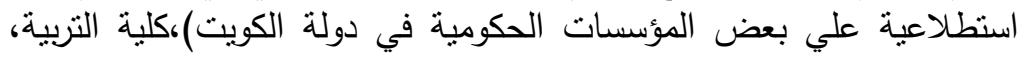

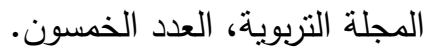
جمال محمد حماد(7 ( + ب)، دور وواقع تمكين المرأة في القطاع غير الرسمي، دراسة حاله

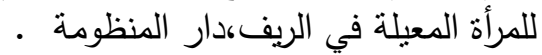

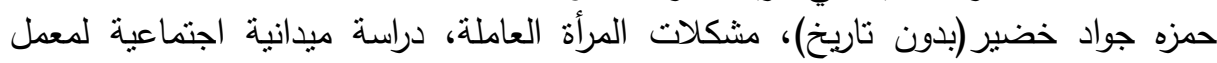

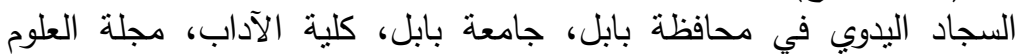

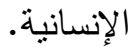

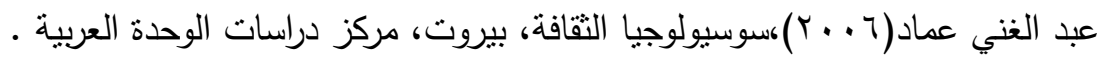

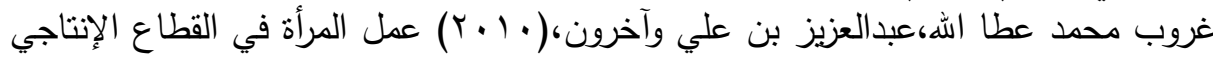
غير الرسمي، رسالة ماجستير جامعة اليرموك، كلية الآداب، الاردن، دار الإنا

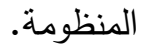

محمد احمد بيومي(ب (911))، علم اجتماع، دار المعرفة الجامعية، القاهرة .

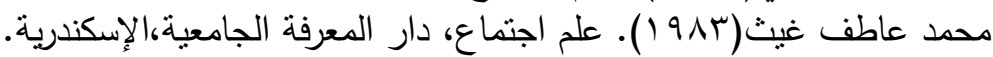

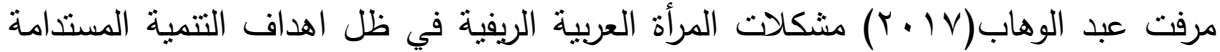

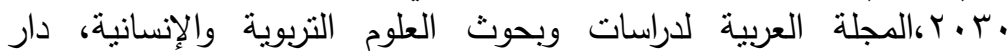

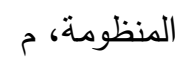

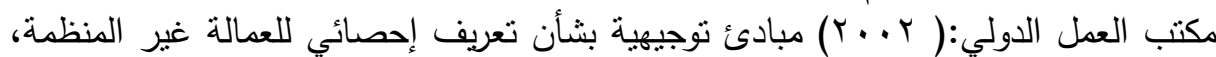

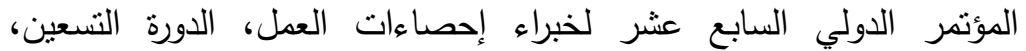

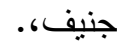

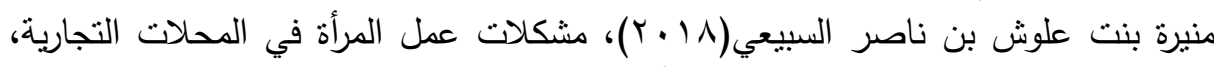

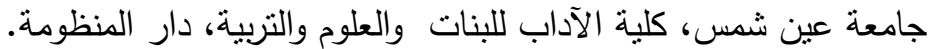

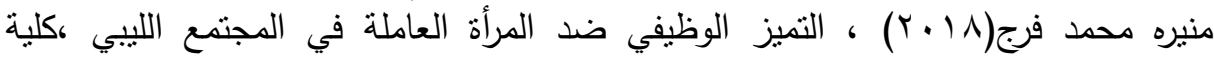

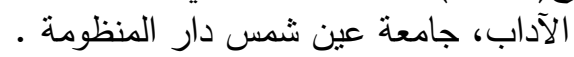

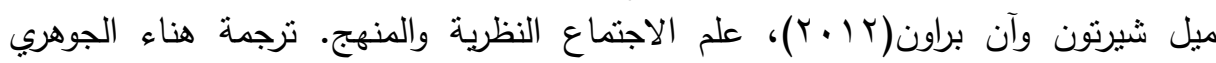

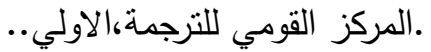

Fornier, Anneleen Erika Hendrika Cornelia(2003): temporary employment and training belgium, katholieke university leuven,

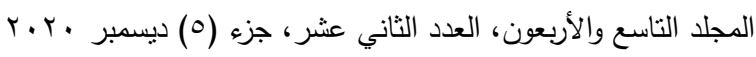

$$
\begin{aligned}
& \text { الترقيم الدولي 0826-1110 1SSN }
\end{aligned}
$$




$$
\begin{aligned}
& \text { مجلة العلوم البيئية } \\
& \text { معهد الدراسات والبحوث البيئة - جامعة عين شمس لئس } \\
& \text { زينب بركة الله محمد وآخرون }
\end{aligned}
$$

Virtanen,Mariana et al: Mental Health and Hostility as Predictors of Temporary Evidence from Tow Prospective Studies. Social Science \&Medicine .voI.61(10),nov 2005,pp.2084-2095.

Henry L. Tischler,( 1990) 'Introduction To Sociology, Library of Congress.3ed edition, Chicago, Pp.78179.

\title{
SOCIAL PROBLEMS OF IRREGULAR WORKFORCE OF FEMALES \\ A FIELD STUDY ON SOHOG GOVERNORATE
}

\section{Zeinab B. Muhammed ${ }^{(1)}$; Hatem A. Ahmed ${ }^{(2)}$ and Alshimaa Bj Amer ${ }^{(2)}$}

1) Post Grad., Student, Institute of Environmental Studies and Research Ain Shams University 2) Department of Environmental Humanities Sciences, Institute of Environmental Studies and Research Ain Shams University

\begin{abstract}
The current study aimed to identify the social problems facing female workers in irregular employment, including the reasons for choosing this type of work, problems and diseases resulting from work, problems of sexual harassment at work, and the customs and traditions prevailing in society that affect the workers. The nature of the informal work was represented in working on agricultural lands for a daily wage. Where the research sample consisted of 20 female workers and was chosen randomly, taking into account the diversity in age, educational level, and years of work. This study was also applied to female workers in agricultural lands in one of the villages of Upper Egypt - the village of Enebis - affiliated to Juhayna Center in Sohag Governorate. The case study approach and the informed interview and observation tool

$$
\begin{aligned}
& \text { المجلد التاسع والأربعون، العدد الثاني عشر، جزء (0) ديسمبر ·.T.T }
\end{aligned}
$$

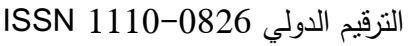




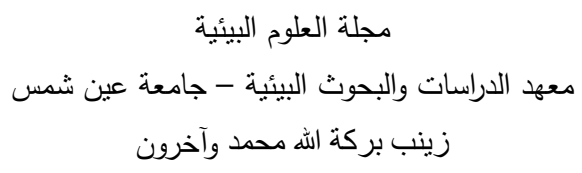

were used, due to the nature of the research community, the type of work and the intended category of the study that only the in-depth qualitative study is compatible with in order for us to reach the research objectives. The results of the research also found that the primary motive for women entering work is an economic motive of $100 \%$ in order to strive to provide the basic and basic needs of female workers and their families. The reason for choosing this work is due to the nature of society and its customs and traditions, which accept only this type of work for women. The prevailing customs and traditions in society represent a great pressure factor for them, such as buying marriage supplies that require a lot of money, so that they can keep pace with the changes that are taking place in society. Female workers are exposed to sexual harassment at work of all kinds. Bias against women in wages, insufficient wages, and her receiving half of what men earn, and the nature of work is the same. And that discrimination in wages is due to discrimination for the sake of sex only, being a man and being a female does not have the right to be equal with men..

\section{Research proposals:}

- The local community plays its role towards the poor groups in society, especially in the villages of Upper Egypt.

- The researcher also suggests to the National Council for Women to pay attention to these marginalized groups of female workers and try to provide them with a help and provide some small projects that guarantee them a more stable and useful work and less harm to the health of workers.

- The researcher also suggests that the Ministry of Social Solidarity seek to provide projects for female workers that would guarantee them the right to live and provide for their needs and the various needs of their families.

Key words: problems - social problems- irregular workforce.

$$
\begin{aligned}
& \text { المجلد التاسع والأربعون، العدد الثاني عشر ، جزء (0) ديسمبر ·r.r. } \\
& \text { الترقيم الدولي }
\end{aligned}
$$

